

\section{DISCLAIMER}

This report was prepared as an account of work sponsored by an agency of the United States Government. Neither the United States Government nor any agency Thereof, nor any of their employees, makes any warranty, express or implied, or assumes any legal liability or responsibility for the accuracy, completeness, or usefulness of any information, apparatus, product, or process disclosed, or represents that its use would not infringe privately owned rights. Reference herein to any specific commercial product, process, or service by trade name, trademark, manufacturer, or otherwise does not necessarily constitute or imply its endorsement, recommendation, or favoring by the United States Government or any agency thereof. The views and opinions of authors expressed herein do not necessarily state or reflect those of the United States Government or any agency thereof. 


\section{DISCLAIMER}

Portions of this document may be illegible in electronic image products. Images are produced from the best available original document. 
GEAP-10054

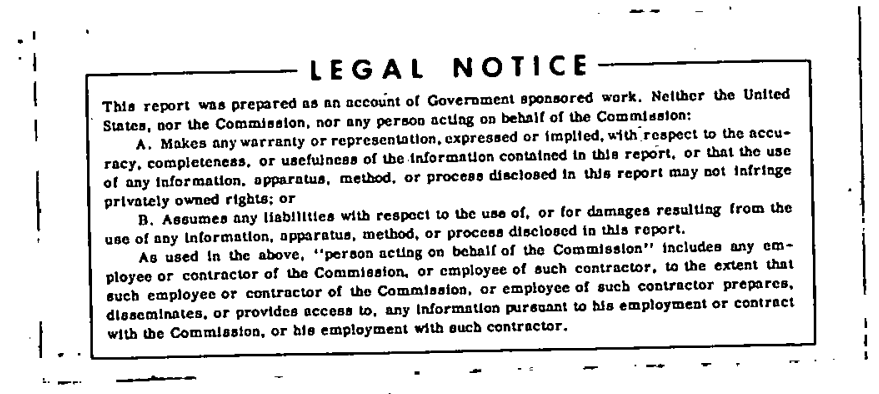

AEC Research and Development Program May 1969

\section{COMPRESSIVE CREEP CHARACTERISTICS OF STOICHIOMETRIC URANIUM DIOXIDE}

P. E. Bohaboy

R. R. Asamoto

A: E. Conti

Approved: 4.6.Sails

W, E. Baily, Project Engineer

Fast Ceramic Reactor Development Program
Approved: $\quad$ E. 2. Suprosei

E. I. Zéhroski, Manayer

Sodium Reactor Technology

Prepared for the

United States Atomir Energy Commission

Under Contract No. AT(04-3)-189

Project Agreement No. 10

Printed in U.S. A. Available from the

Clearing House for Federal Scientific and Technical Information

National Bureau of Standards, U. S. Department of Commerce

Springield, Virginiu

Price: $\$ 3.00$ per copy

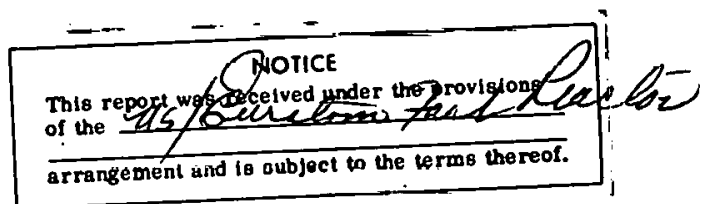




\section{LEGAL NOTICE}

This report was prepared as ans account of Govertwnent sponsored work. Neitber the United States, nor the Commission, nor any person acting on bebalf of the Commission:

A. Makes any warranty or representation, expressed or implied, with respect to the accuracy, completeness, or usefulness of the information contained in this report, or that the use of any information, apparatus, metbod, or process disclosed in this report may not infringe privately owned rights; or

$B$. Assumes any liabilities with respect to the use of, or for damages resulting from the use of any information, apparatus, method, or process disclosed in this report.

As used in the above, "person acting on bebalf of the Commission" includes any employee or contractor of the Commission, or employee of such contractor, to the extent that sucb employee or contractor of the Commission, or employee of such contractor prepares, disseminates, or provides access to, any information pursuant to bis employment or contract with the Commission, or bis emplovment with such contractor. 


\section{TABLE OF CONTENTS}

ABSTRACT

iv

SECTION I. INTRODUCTION

I-1

SECTION II. LITERATURE REVIEW

II-1

SECTION III. CONCLUSIONS

III-1

SECTION IV. EXPERIMENTAL DESIGN IV-1

4.1 Test Furnace $\quad$ IV -1

4.2 Instrumentation IV-1

4.3 Test Specimens IV -1

4.4 Experimental Procedure IV -5

SECTION V. EXPERIMENTAL DATA AND DISCUSSION OF RESULTS V-1

$\therefore \quad 5.1$ Creep of $\mathrm{UO}_{2}$ as a Function of Temperalure, Stress, Grain

$\sqrt{-1}$

Size and Density $\quad \mathrm{V}-1$

5.2 Effect of Density on the Creep of $\mathrm{UO}_{2} \quad \mathrm{~V}-1$

5.3 Effect of Grain Size on Creep Rate of $\mathrm{UO}_{2} \quad \mathrm{~V}-7$

5.4 Metallographic Observations of Strained $\mathrm{UO}_{2}$ Samples $\quad \mathrm{V}-7$

$\begin{array}{ll}\text { 5.5 Comparison of Experimental Results with Previously } & \text { V-11 } \\ \text { Reported Creep Data on } \mathrm{UO}_{2} & \end{array}$

APPENDIX A PRECISION OF EXPERIMENTAL TECHNIQUE A-1

APPENDIX B ANALYSIS OF EXPERIMENTAL DATA B-1

APPENDIX C GRAIN GROWTH OF UO $\mathrm{UO}_{2}$ SAMPLES C-1

APPENDIX D PROCEDURE FOR NORMALIZING EXPERIMENTAL DATA D-1

ACKNOWLEDGMENTS -1-

REFERENCES -2-

DISTRIBUTION LIST 


\section{LIST OF ILLUSTRATIONS}

$\underline{\text { Page }}$

FIGURE

TITLE

4-1 Mechanical Properties Test Furnace

IV-2

$4-2$

Schematic Drawing of Mechanical Properties Test Furnace

IV-3

4-3 Schematic of the Mechanical Properties Test Apparatus

IV -5

$4-4$

As-Fabricated Micrustructure of $\mathrm{UO}_{2}$ Test Specimens

IV- 6

$4-5$

As-Fabricated Microstructure of $\mathrm{UO}_{2}$ Test Specimens

IV-7

$4-6$

As-Fabricated Microstructure of $\mathrm{UO}_{2}$ Test Specimens

IV -8

5-1 Comparison of Normalized Data with Calculated Creep Rates for $97 \% \mathrm{TD} ; 14$ Micron $\mathrm{UO}_{2}$

$\mathrm{V} \rightarrow 2$

5-2 Comparison of Normalized Data with Calculated Creep Rates for $95 \%$ TD, 14 Micron $\mathrm{UO}_{2}$

V-3

Comparison of Normalizèd Data with Calculated Creep Rates for $82 \% \overline{\mathrm{T}} \mathrm{D}, .11$ Microns $\mathrm{UO}_{2}$

$\mathrm{V}-4$

Effect of Density on Crecp Ratc of $\mathrm{UO}_{2}$

$\mathrm{V}-5$

$5-4$

Creep Rate as a Function of Density at 1000 and 8000 psi

\section{5-5}

$5-6$

Effect of Grain Size on Creep Rate of $\mathrm{UO}_{2}$

$5-7$

Creep Rate as a Function of Grain Size at $100 \dot{0}$ psi

V-9

$5-8$

Microstructure of $\mathrm{UO}_{2}$ Sample Tested at $1750^{\circ} \mathrm{C}$ and $5000 \mathrm{psi}$

V-10

$5-9$

Microstructure of $\mathrm{UO}_{2}$ Sample Tested at $1750^{\circ} \mathrm{C}$ and $3700 \mathrm{psi}$

$\mathrm{V}-10$

$5-10$

C'omparison of Results with Bend I'est Creep Data of $\mathrm{UO}_{2}$

$\mathrm{V}-12$

5-11 Comparison of Experimental Results with Previously Reported Compression Creep Data of $\mathrm{UO}_{2}$

V-13 


\section{LIST OF ILLUSTRATIONS (Continued)}

Page

FIGURE

TITLE

A-1 Increase in the Cross-Section Area Versus the Percent Strain in the Sample Length

A-2

B-1 Frequency Polygon Showing the Distribution of the Percent Deviations Between Experimental and Calculated Creep Rates

B-6 $\cdots$

C-1 Increase in Average Grain Size of $\mathrm{UO}_{2}$ as a Function of Time and Temperature

C-2

\section{LIST OF TABLES}

TABLE

\section{TITLE}

4-1 Fabrication History of $\mathrm{UO}_{2}$ Test Samples $\quad$ IV-5

4-2 Characterization of Sintered $\mathrm{UO}_{2}$ Pellets

IV -9

4-3 Typical Spectrographic Analysis Result

IV -9

B-1

Comparison of Experimental Data and Calculated Creep Rates 


\section{ABSTRACT}

"The creep of cold-pressed and sintered stoichiometric uranium dioxide was measured in compression as a function of temperature, stress, grain size, and theoretical density. The creep rate of uranium dioxide as a function of these parameters is described by the modified Arrhenius equation given below:

$$
\dot{\epsilon}=\mathrm{A} \sigma \exp (-90,000 / \mathrm{RT})+\mathrm{B} \sigma^{4.5} \exp (-132,000 / \mathrm{RT})
$$

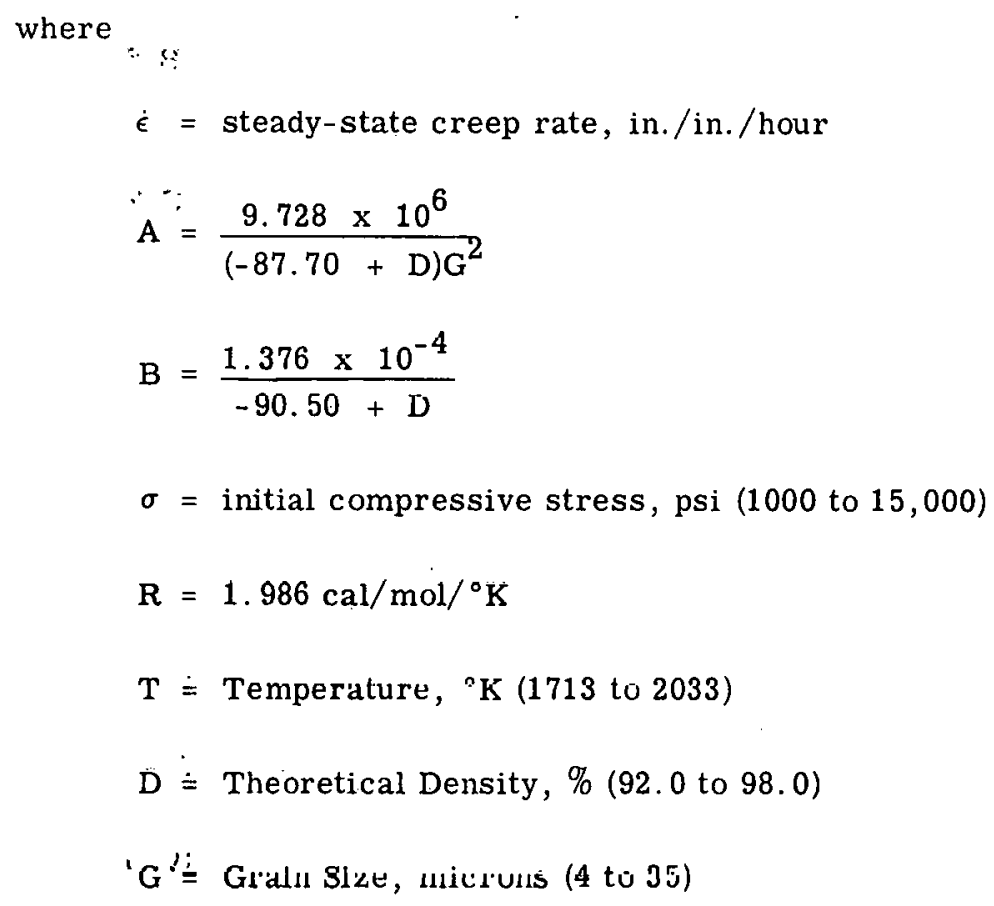

The strain rate of uranium dioxide was found to be inversely proportional to the square of the grain size at low stresses and inversely related to the density. The experimental results fit this equation with $\pm 32 \%$ with a confidence level of $90 \%$.

This type of behavior of uranium dioxide is in agreement with existing theoretical descriptions of creep mechanisms, and the correlation indicates that thermally aclivated creep in uranium dioxide results from a combination of stress-enhanced diffusion, dislucation motion, and sliding at grain boundaries. The mechanism which dominates and controls the creep rate is dependent on the specific temperature, stress, grain size, and density.

Activation energies for uranium dioxide creep were calculated to be $90 \mathrm{Kcal} / \mathrm{mole}$ in the low stress regions and $132 \mathrm{Kcal} / \mathrm{mole}$ in the high stress regions.

Data previously reported on the creep of uranium dioxide agreed well with the results of this investigation. The effects of density and grain size on the creep behavior of uranium dioxide were evaluated and the relationship of these material parameters to nuclear fuel element design discussed. This work was done as a preliminary to the measurement of creep of mixed uranium-plutonium oxide. 


\section{INTRODUCTION}

The creep properties of a ceramic oxide nuclear fuel are an important parameter in determining the performance potential of a fast reactor fuel element. During reactor operation, stresses develop within the oxide fuel as a result of the interaction with the cladding, differential thermal expansion, and from volume changes induced by fission products. The increase in the radial stress component with fuel burnup can result in high hoop stresses within the cladding material. The resultant fuel-cladding interaction may lead to significant plastic deformation and fracture of the cladding material and limit the life of the fuel pin in the reactor. In a Fast Ceramic Reactor, fuel burnups in excess of $1000,000 \mathrm{MWd} / \mathrm{Te}$ will be necessary. Consequently an understanding of the mechanical properties of the fuel is essential to permit the effective design of a fuel element which minimizes cladding strain during the life of the core.

To aid in acquiring an understanding of this type of material behavior, a test apparatus has been constructed to permit definitive measurement of the creep rate of mixed plutoniumuranium oxide fuels under conditions similar to those of interest in reactor operation. The trial operation of this equipment was performed on uranium dioxide (natural and depleted) and the results are presented in this report.

The inherent radial temperature gradient in a fuel element results in gross microstructural changes acruss the fuel radius. These changes include grain growth and fuel migration during the formation of columnar grains, resulting in an increase in the initial fuel density. A small ring of fuel directly adjacent to the cladding essentially maintains its as-fabricated density. Since creep is a function of stress, lemperature, and density, the deformation behavior of the oxide fuel will vary within the different regions of the fuel matrix. The overall response of the entire fuel volume will determine the extent of the resultant fuel-cladding interaction.

Present fuel designs incorporate porosity within the fuel to accommodate fuel volume increases and minimize the subsequent strain in the clad. The success of this concept is determined by the ability of the oxide fuel to creep into the available pore volume.

Experimental data on which to base predictions of fuel swelling have been relatively sparse. The purpose of this investigation was to provide useful information on the out-of-reactor creep behavior of oxide fuels under various controlled conditions of stress, temperature, grain size, and density: 'By knowing how a fuel behaves as a function of these variables, it becomes possible to make more reliable predictions of the fuel-cladding interaction forces as well as fuel redistribution. Subsequent experiments on mixed plutonium uranium oxide fuels and in-reactor creep tests are planned as extensions of the current work. The variables of stoichiometry and plutonium. content will be added to the list of parameters to be investigated.

A compression test was chosen for this investigation. Under reactor operating conditions, the fission product swelling and differential thermal expansions result in radial force components that are opposed by clad and fuel restraint. These conditions are best duplicated in a compression test rather than in a bent beam test.

The results obtained in this investigation are reported herein. 


\section{LITERATURE REVIEW}

\section{A. Creep Mechanisms in Ceramic Materials}

The creep deformation of single phase polycrystalline ceramics is a complex process generally attribuled to stress enhanced diffusion, dislocation movement, and grain boundary sliding. These thermally activated processes which become operative at temperatures of approximately half the melting point can contribute simultaneously to the overall deformation of the material. The mechanism which dominates the behavior, however, is directly related to the temperature, stress, density, grain size and impurity content. Changes in any of these variables can alter the controlling mechanism and significantly change the mechanical deformation behavior.

Most experimental data on the creep behavior of ceramic materials can be described by the following form of the Arrhenius equation

$$
\dot{\epsilon}=A \sigma^{n} \exp (-Q / R T)
$$

where

$$
\begin{aligned}
& \dot{\epsilon}=\text { creep rate } \\
& \mathbf{A}=\text { material parameter determined by microstructure } \\
& \sigma=\text { stress } \\
& \mathbf{n}=\text { stress exponent } \\
& \mathbf{Q}=\text { activation energy } \\
& \mathrm{R}=\text { gas constant } \\
& \mathrm{T}=\text { temperature }
\end{aligned}
$$

Attempts have been made lo correlate the parameters $A, n$, and $Q$ with existing creep theories. In general the experimentally determined values of $Q$ have been consistent with the activation energy for cation self-diffusion (the slowest moving ion in the material). However, because of uncertainties in the experimental data, only rarely has it. heen pnssihle to unequivocally establish a relation between a particular creep mechanism and the observed behavior. (1)

\section{Stress Enhanced Diffusion}

At low stress, diffusional or Nabarro-Herring ${ }^{(2,3)}$ creep is operative. Deformation results from the flow of vacancies from grain boundaries in tension to those in compression. This type of material response leads to strain rates which are linearly dependent on the stress and inversely proportional to the square of the grain size $\left(\dot{\epsilon} \propto \sigma / G^{2}\right)$.

Dislocation Movement

The movement of dislocations due to applied shear stresses within the crystal structure results in a macroscopic movement of materlal and permanent deformation. At high 
temperatures, dislocation climb can occur and results in an increase in deformation rate by allowing dislocations to surmount barriers (impurity precipitates, porosity, grain boundaries, etc.) which normally would restrict dislocation movement. Weertman ${ }^{(4)}$ has proposed that high temperature dislocation movement should result in the creep-rate being proportional to stress raised to the 4.5 power $\left(\dot{\epsilon} \propto \sigma^{4 \cdot 5}\right)$.

\section{Grain Boundary Sliding}

The third process by which deformation can occur in polycrystalline ceramics is grain boundary sliding. The grain boundaries, which are areas of poor lattice registry and high dislocation density, give rise to a complex deformation process which is not well understood. Without the occurrence of either diffusional or dislocation movement mechanisms to change the grain shape during deformation, grain boundary sliding cannot occur on a continuous basis while maintaining grain boundary continuity. However, grain boundary sliding in cooperation with other deformation mechanisms can have the effect of increasing the overall creep rate and reducing the geometric restrictions imposed on the other mechanisms. $(5)$

B. Creep of Stoichiometric $\mathrm{UO}_{2}$

The creep behavior of single crystal and polycrystalline $\mathrm{UO}_{2}$ has been studied by several investigators. An excellent detailed review of all published data has been prepared by Wolfe and Kaufman. ${ }^{(6)}$. In general this data has been more qualitative than quantitative. The effects of temperature, stress, density and grain size on the steady state creep rate have been observed, and general trends showing the relationship between the creep rate and these variables have been stated. However, a lack of sufficient quantitative data has prevented the development of a specific expression which reasonably predicts the creep behavior of $\mathrm{UO}_{3}$ over wide ranges of the parameters.

The creep of single crystal $\mathrm{UO}_{2}$ was studied by Armstrong, et al. ${ }^{(7)}$ A bend test was used, and the measurements were made between 1340 and $1685^{\circ} \mathrm{C}$ under maximum fiber stresses of 3600 to $8000 \mathrm{psi}$. Fitting these data to the Arrhenius equation gave an activation energy (Q) of $118 \mathrm{Kcal} / \mathrm{mole}$ and a stress exponent value (n) of 3.3 .

Scott, et al, ${ }^{(8)}$ used a bend test to study the creep of polycrystalline $\mathrm{UO}_{2}$. The activation energy for $95 \%$ dense samples was calculated to be greater than $95 \mathrm{Kcal} / \mathrm{mole}$.

Armstrong, et al ${ }^{(9)}$ also performed bend tests on polycrystalline $\mathrm{UO}_{2}$. The stoichiometric samples had a density range of 93 to $98 \%$ and a grain size range of 6 to 40 microns. The temperature was varied between 1250 and $1400^{\circ} \mathrm{C}$, and the stress from 700 to $16,000 \mathrm{psi}$. Two distinct modes of behavior were observed. Bclow 10,000 psi, the creep rate increased with stress in a nearly linear manner. The following expression* describing the creep of $96 \%$ dense, 6 micron samples as a function of stress and lemperalure was ubtained:

*Equation appearing in literature has been modified to report creep in units of in/in/hour -personal communication from A. R. Causey (for W. M. Armstrong) to J. L. Smith, September 27, 1966. 


$$
\dot{\epsilon}=2 \times 10^{4} \sigma^{1.3} \exp (-91,000 / \mathrm{RT}) \quad \mathrm{in} / \mathrm{in} / \mathrm{hr}
$$

Above $10,000 \mathrm{psi}$, the creep rate increased more rapidly with stress, and the stress exponent $\mathrm{n}$ was calculated to be much greater than one. Grain boundary sliding was reported to occur during creep deformation. However, no correlation between the creep rate and grain size was found. Increased porosity in the grain boundaries was observed to facilitate creep deformation.

Compression testing of $\mathrm{UO}_{2}$ has been reported by Poteat and Yust ${ }^{(10)}$ and by Wolfe and Kaufman. (6) The creep data of Poteat and Yust was determined at temperatures from 1430 to $1666^{\circ} \mathrm{C}$ under constant load, with the stresses from 2000 to 11,000 psi. The samples were $96.3 \%$ dense and 10 micron average grain size. In general the results were similar to those of the bend tests. A transition in the steady state creep rate from a viscous flow at low stresses $(\dot{\epsilon} \propto \sigma)$ to a power law relation at stresses greater than $6000 \mathrm{psi}\left(\dot{\epsilon} \propto \sigma^{4 \cdot 5}\right)$ was observed. Activation energies varied from 83 to $97 \mathrm{Kcal} / \mathrm{mole}$.

Wolfe and Kaufman ${ }^{(6)}$ investigated the deformation of samples with grain sizes of 18 and 55 microns. The test temperatures ranged from 1600 to $2000^{\circ} \mathrm{C}$ and the initial stress from 1000 to $7500 \mathrm{psi}$. The stress at which the transition in creep behavior occurred was found to be strongly affected by grain size. This transition took place at about 3000 psi for the 18 micron material and at less than 2000 psi for the 55 micron samples. At low stresses: the smaller grain size material exhibited higher creep rates under similar test conditions. The activation energy for creep was reported to be $71 \mathrm{Kcal} / \mathrm{mole}$.

In general, the experimental data reported in the literature to date show an extensive scatter, only part of which can be associated with variations in material grain size and stoichiometry. However, the data do indicate that at relatively low stresses (1000 to $3000 \mathrm{psi})$ the creep rate is almost directly proportional to stress $(\dot{\epsilon} \propto \sigma)$. Grain boundary. sliding contributes to the overall creep deformation, and small grain size material creeps more rapidly than large grain size samples.

At higher stresses ( $\sim 6000 \mathrm{psi}$ ) a transition in the creep behavior occurs and creep rates increase more rapidly with increasing stress $\left(\dot{\epsilon} \propto \sigma^{4}\right.$ to 5$)$. The stress ạt. which this transition takes place decreases with increasing grain size. The dominant creep mechanism here seems to be dislocation motion. Grain size does not affect creep rates at high stresses.

The calculated activation energies for creep range from 71 to $118 \mathrm{Kcal} / \mathrm{mole}$. Comparison of these values with activation energy values for the self-diffusion of the uranium atom in UO2 (70 to $108 \mathrm{Kcal} / \mathrm{mole})^{(11-13)}$ shows reasonable agreement. 


\section{CONCLUSIONS}

The experimental results of this investigation indicate that:

1. The steady state creep behavior of stoichiometric polycrystalline uranium dioxide under compressive loads can be described by the relationship:

$$
\dot{\epsilon}=\mathrm{A} \sigma \exp (-90,000 / \mathrm{RT})+\mathrm{B} \sigma^{4.5} \exp (-132,000 / \mathrm{RT})
$$

where

$$
\begin{aligned}
& \dot{\epsilon}=\text { steady-state creep rate, in/in/hour } \\
& A=\frac{9.728 \times 10^{6}}{(-87.70+D) G^{2}} \\
& B=\frac{1.376 \times 10^{-4}}{-90.50+D} \\
& \sigma=\text { initial compressive stress, psi }(1000-15,000) \\
& R=1.906 \text { cal } / \text { inol } /{ }^{\circ} \mathrm{K} \\
& T=\text { Temperature },{ }^{\circ} \mathrm{K}(1713-2033) \\
& D=\text { Theoretical Density, } \%(92.0-98.0) \\
& G=\text { Grain Size, microns }(4-35)
\end{aligned}
$$

For the experimental procedures and apparatus used in this investigation, the actual creep measurements made on the $\mathrm{UO}_{2}$ samples fall within $\pm 32 \%$ (90\% confidence level) of the creep rates salsulated from this expression.

2. The experimental results are in agreement with existing theoretical creep mechanisms, indicating that thermally activated creep in $\mathrm{UO}_{2}$ results from the combination of stress enhanced diffusion, dislocation motion, and grain boundary sliding. The change in activation energy from 90 to $132 \mathrm{Kcal} / \mathrm{mole}$ with increasing stress indicates a change in the controlling creep mechanism.

3. At low applied stress $(\tilde{<} 3000 \mathrm{psi})$ the creep behavior of $\mathrm{UO}_{2}$ exhibits a high dependence un graln stze ( $\dot{\epsilon} \alpha 1 / G^{2}$ ). This material parameter consequently is an important consideration along with porosity in designing fuel elements to minimize clad distortion resulting from fission product swelling and differential thermal expansion.

4. Comparison of previously reported creep data on polycrystalline $\mathrm{UO}_{2}$ with the results of this investigation are in good agreement. 


\section{EXPERIMENTAL DESIGN}

\subsection{TEST FURNACE}

A photograph of the test furnace used in this investigation is presented in Figure 4-1. The internal operation of the furnace is illustrated in Figure 4-2. The entire bottom plate of the furnace assembly was lowered by two hydraulic cylinders for loading and unloading the test sample. With the furnace in the test position, the compressive load was applied on the sample by two tungsten plungers. The upper plunger was rigidly fixed to the top of the furnace. The lower plunger was free to move vertically through a linear bearing and bellows in the bottom plate. Both plungers were thermally insulated from the vessel shell by pyrolitic carbon spacers. A uniform heat zone was provided by a cylindrical tungsten mesh resistance heating element that was suspended from the top of the furnace. Temperature control was maintained by providing a constant power input to the heating element. A boron nitride muffle was placed around the test specimen, and the entire heating zone was surrounded by tungsten heat shields to minimize heat losses.

\subsection{INSTRUMENTATION}

The hydraulic load on the test specimen was measured using a 0-5000 psig bourdon tube pressure gauge. Scale divisions were in 5 psi increments and the accuracy was $0.1 \%$ full scale. The load was maintained at a constant level during testing by a gas-hydraulic system. A schematic of the design is included in Figure 4-3. A floating gas/oil piston compensated for any change in the hydraulic pressure resulting from deformation of the test sample. A high pressure gas bottle (helium) and regulator were used to maintain the constant gas pressure.

The furnace cover gas of premixed nitrogen - 6\% hydrogen was maintained slightly above atmospheric pressure $(0-6$ psig). This pressure was controlled by a low pressure regulator and measured using a 0 to $10 \mathrm{psig}$ gauge. Divisions were in one ounce increments and the accuracy was $2-3 \%$.

Creep of the $\mathrm{UO}_{2}$ test specimens was measured by two techniques. A precision optical cathetometer with an accuracy of \pm .0001 " was used to measure sample length changes by sighting through the observation port located on the front of the furnace. The emissivity differences at the interfaces between the $\mathrm{UO}_{2}$ and the tungsten plungers resulted in sharp visible lines for making the length measurements. The second measure of creep was obtained from the output of a linear variable differential transformer (LVDT) which monitored the movement of the bottom tungsten plunger. The movement of this plunger was directly proportional to the deformation of the test specimen. The signal of the LVDT was amplified and recorded on a continuous millivolt pen recorder. The creep rate of the $\mathrm{UO}_{2}$ was then obtained from this graph of plunger movement versus time.

\subsection{TEST SPECIMENS}

Uranium dioxide test samples having various combinations of grain size and theoretical nsity were prepared by conventional cold pressing and sintering techniques. The fabrication 


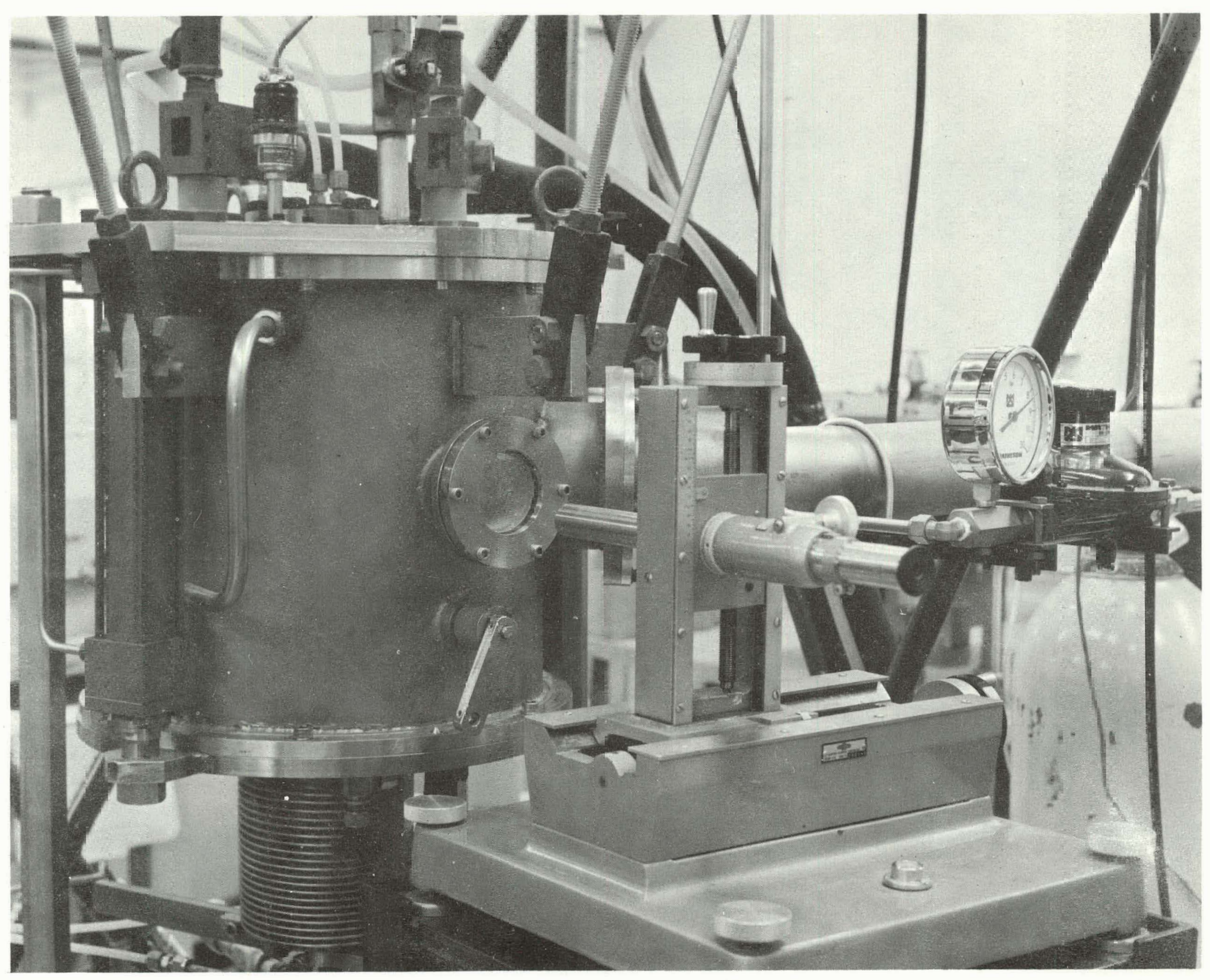

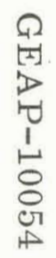




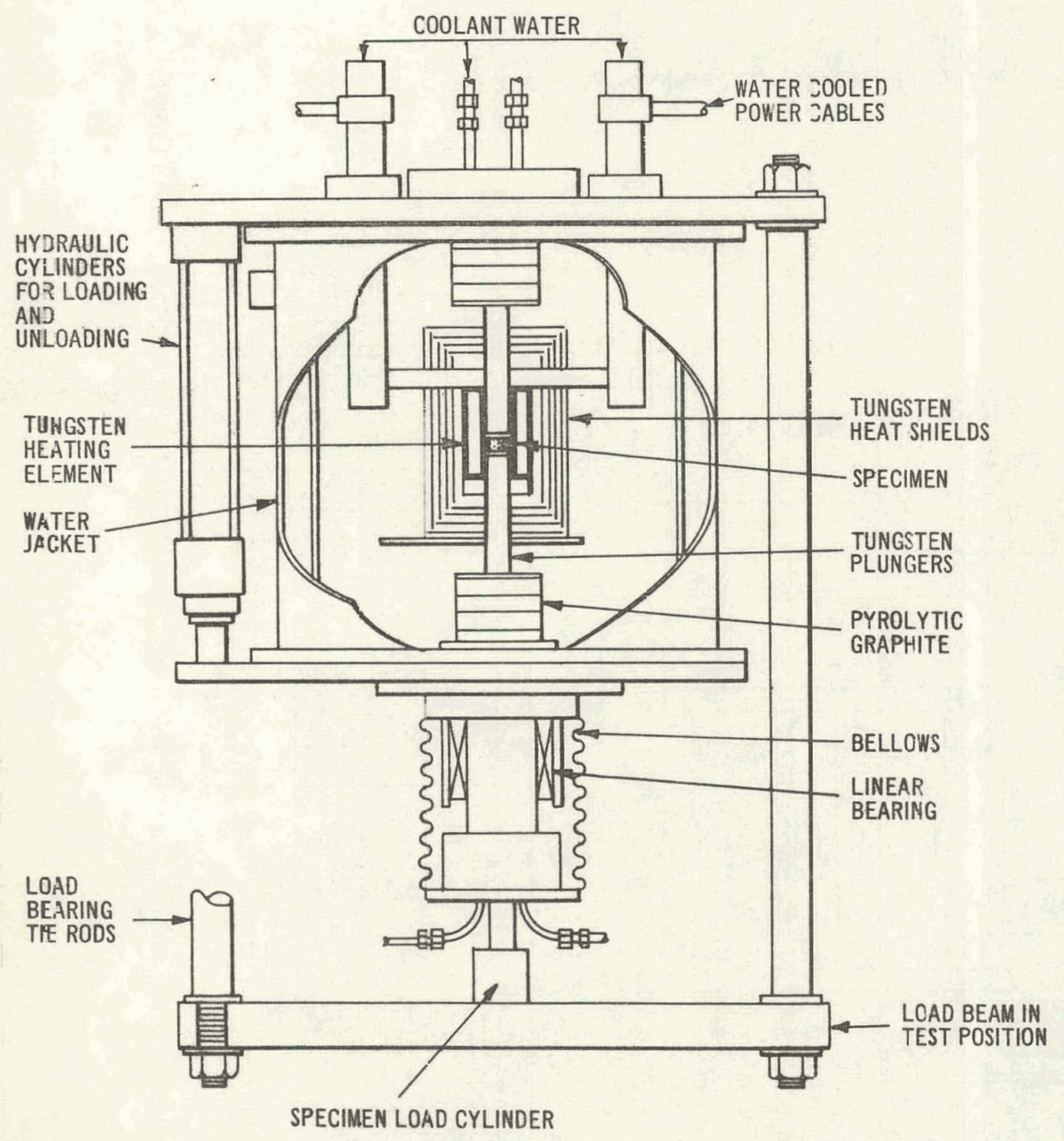

TEST POSITION
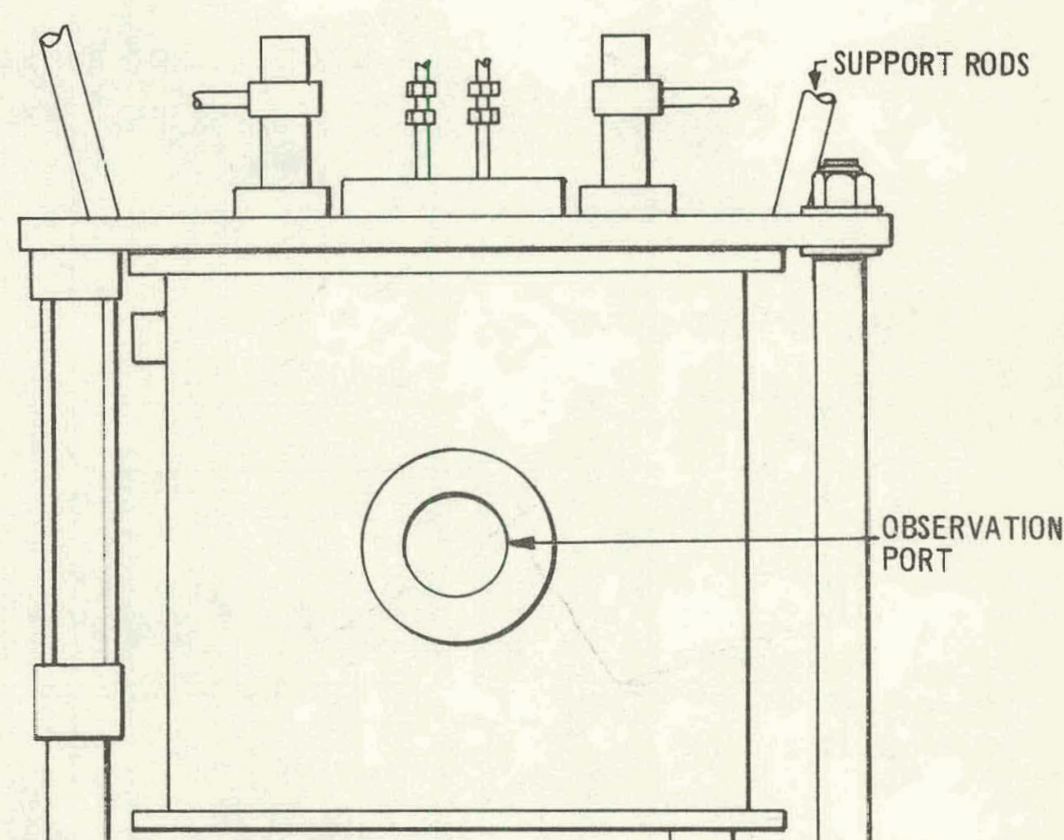

界

Figure 4-2. Schematic Drawing of Mechanical Properties Test Furnace 


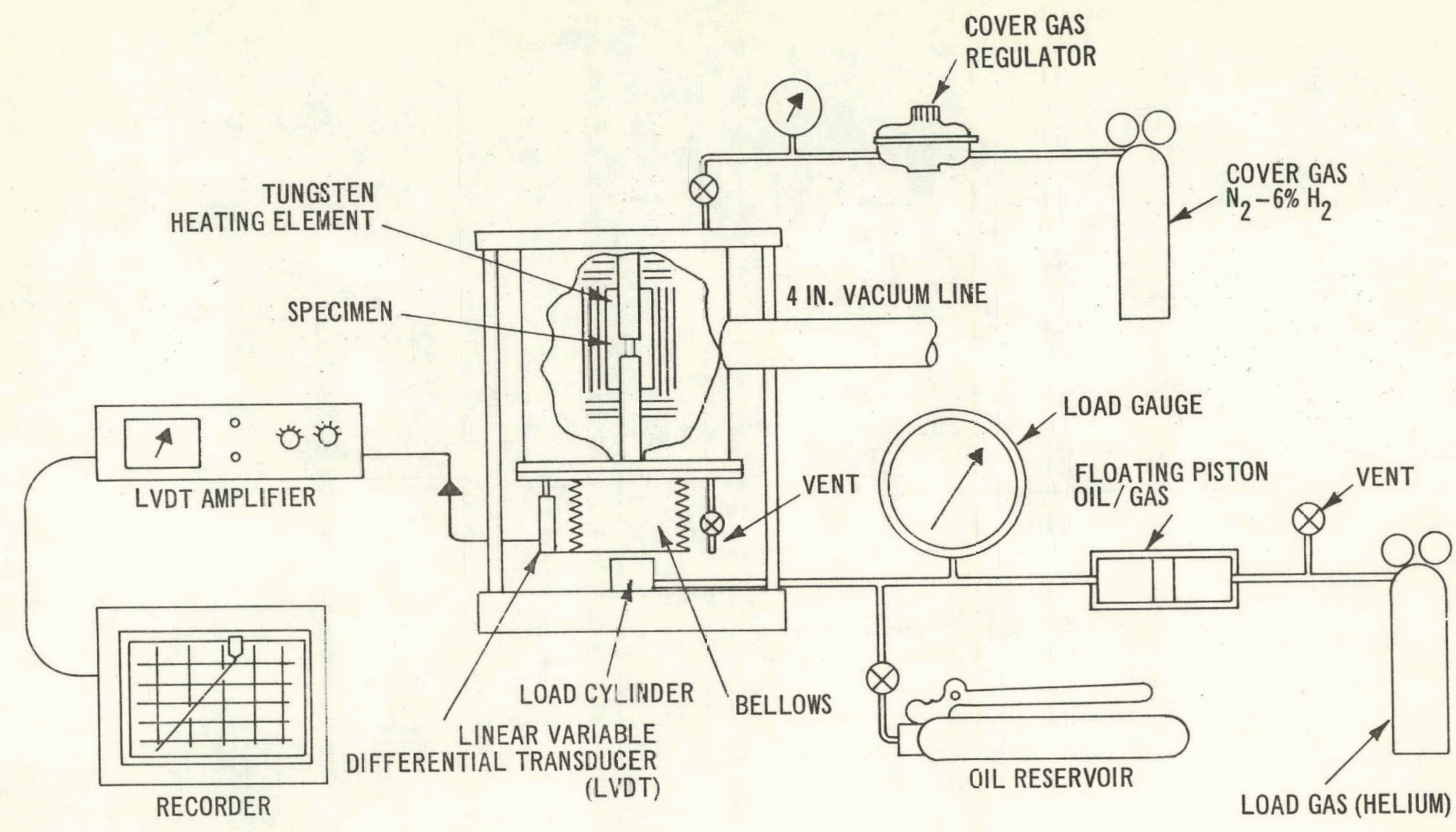


history of individual groups of test cylinders (pellets) is presented in Table 4-1. The cylinders were formed by two directional pressing of depleted or natural uranium-dioxide powders in cylindrical steel dies. The pressed pellets were densified by isostatic pressing and/or sintered in a dry hydrogen atmosphere. After sintering, the pellets were centerless ground to a uniform diameter, ultrasonically cleaned, and refired in dry hydrogen $\left(-80^{\circ} \mathrm{F}\right.$ dewpoint) for 3 to 6 hours at $1100^{\circ} \mathrm{C}$. This final step was intended to reduce any stoichiometry increase that might have occurred during the grinding process.

Table 4-1

Fabrication History of $\mathrm{UO}_{2}$ Test Samples

\begin{tabular}{|c|c|c|c|}
\hline $\begin{array}{c}\text { Batch } \\
\text { Designation } \\
\end{array}$ & $\begin{array}{c}\mathrm{UO}_{2} \\
\text { Enrichment } \\
\end{array}$ & $\begin{array}{c}\text { Sintering } \\
\text { Temperature }\left({ }^{\circ} \mathrm{C}\right) \\
\end{array}$ & $\begin{array}{c}\text { Sintering } \\
\text { Time (Hours) } \\
\end{array}$ \\
\hline B & Natural & 1690 & 4 \\
\hline $\mathrm{C}$ & Natural & 1690 & 4 \\
\hline $\mathrm{E}$ & Natural & 1650 & 48 \\
\hline F & Depleted & 1650 & $4-1 / 2$ \\
\hline G & Depleted & 1735 & 40 \\
\hline I & Depleted & 1600 & 4 \\
\hline
\end{tabular}

Samples of the finished pellets were analyzed for $\mathrm{O} / \mathrm{U}$ ratio by a combination of thermogravimetric techniques and coulometric titration. Polished metallographic sections of the as fabricated samples were also prepared. These sections were etched* and grain size determined by a grain boundary intercept method. (14) Representative characterization of the various groups of test pellets are given in Table 4-2, and the as fabricated pellet microstructures are shown in Figures 4-4 through 4-6. During the fabrication, emphasis was placed on obtaining samples with uniform grain size and microstructure.

Spectrographic analyses were performed on both the "as-fabricated" specimens and on specimens that had been creep tested. Results of the analyses showed that the impurity content of all samples tested was less than $200 \mathrm{ppm}$. A typical spectrographic analysis is given in Table 4-3.

\section{4 EXPERIMENTAL PROCEDURE}

The $\mathrm{UO}_{2}$ test pellet and boron nitride muffle were placed on the lower tungsten ram. The entire lower assembly was then hydraulically raised and secured in the test position. The furnace chamber was evacuated to less than 5 microns pressure and back filled with a nitrogen-6\% hydrogen cover gas mixture. This procedure was repeated a minimum of three times. Following the final minutes.

*Etching agent was a $10 \% \mathrm{H}_{2} \mathrm{SO}_{4}-90 \% \mathrm{H}_{2} \mathrm{O}_{2}$ solution that was applied for one to three 


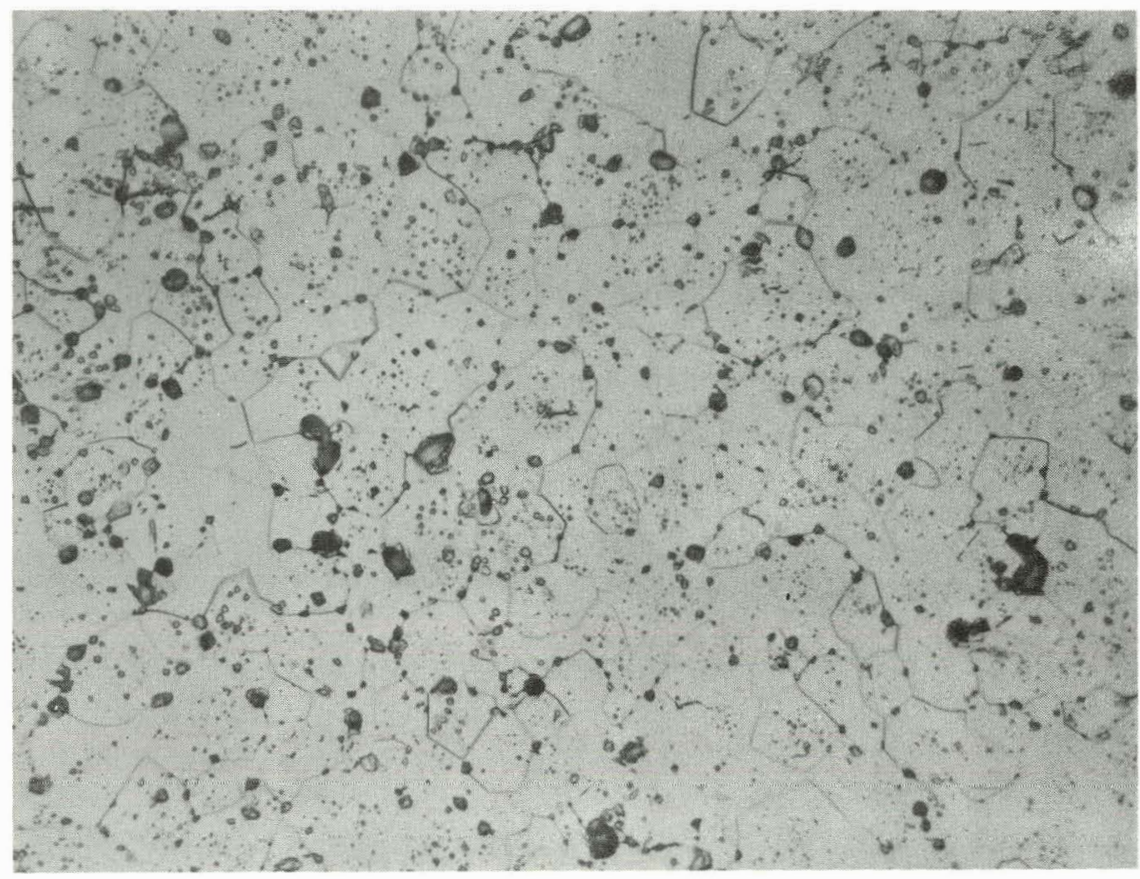

Group B

$500 x$

94.8\% TD

Etched

14 microns

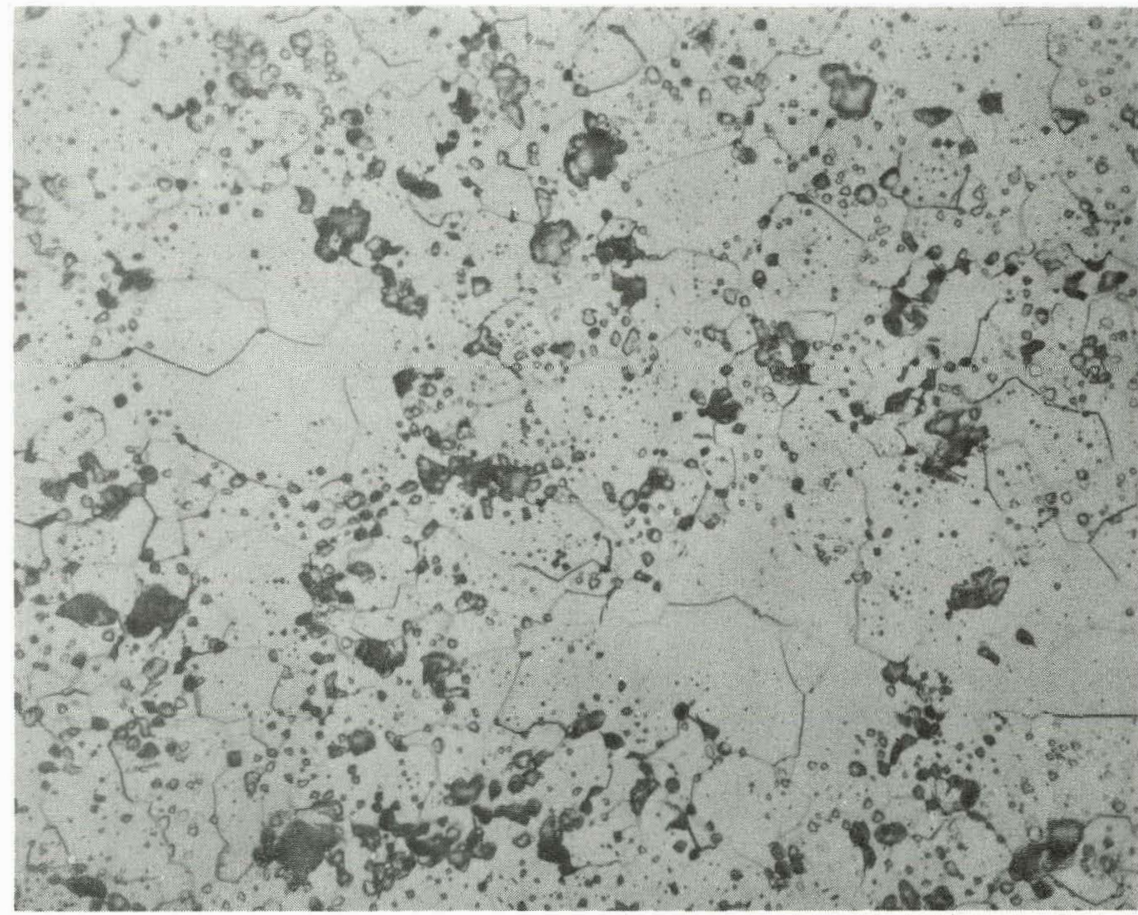

Group C

$500 x$

92.4\% TD

Etched

14 microns

Figure 4-4. As-Fabricated Microstructure of $\mathrm{UO}_{2}$ Test Specimens 

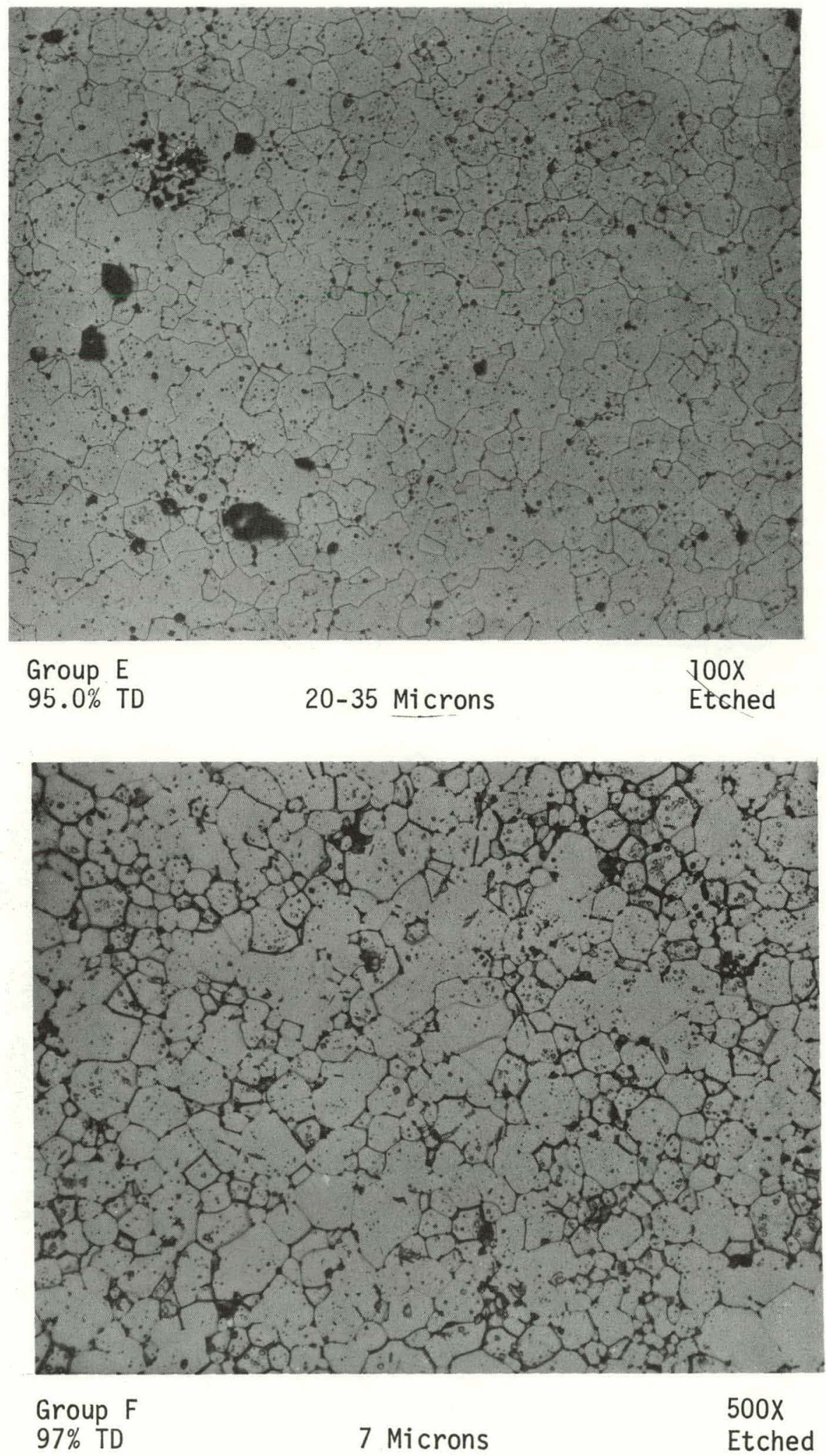

Figure 4-5. As-Fabricated Microstructure of $\mathrm{UO}_{2}$ Test Specimens 

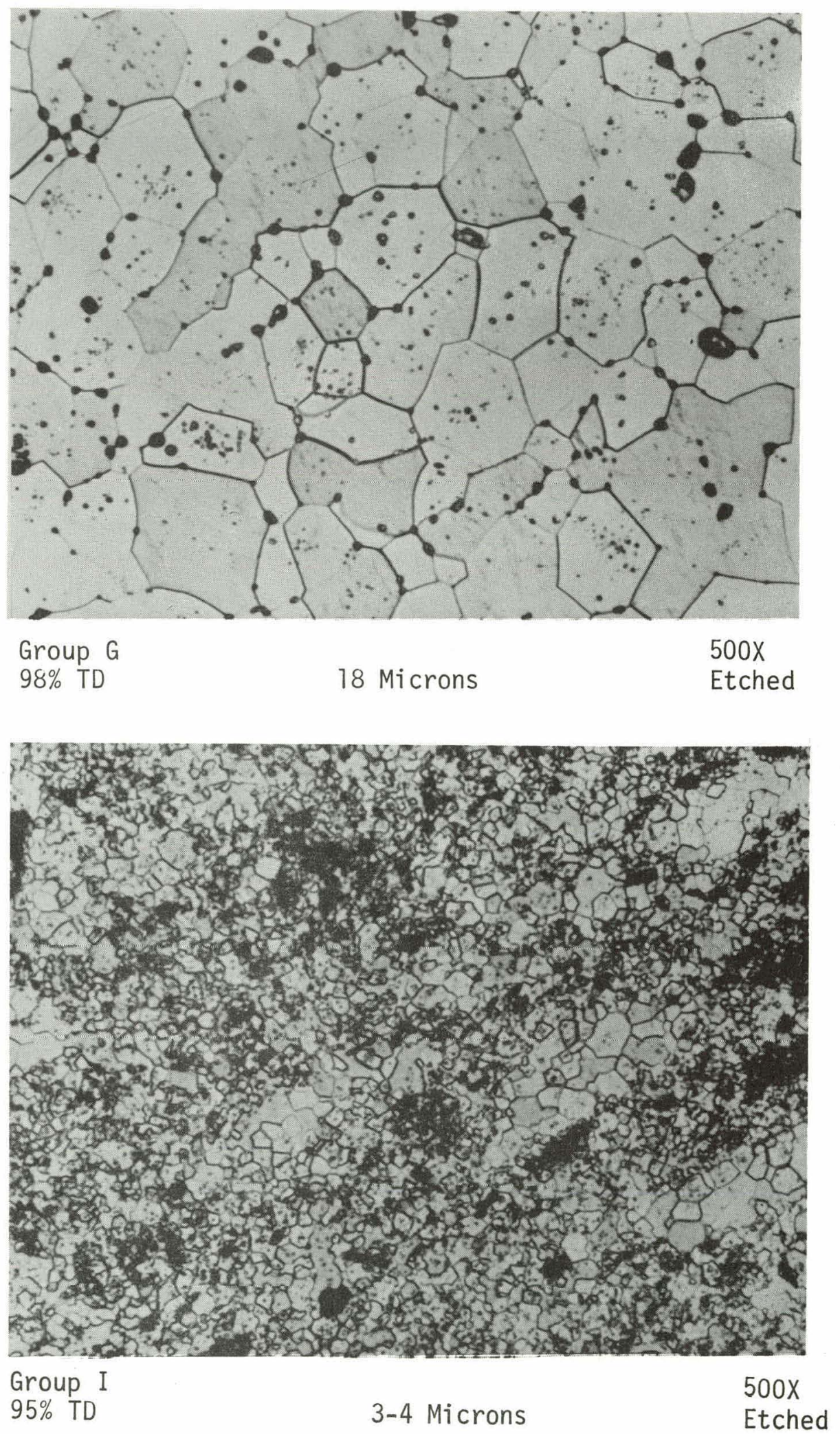

Figure 4-6. As-Fabricated Microstructure of $\mathrm{UO}_{2}$ Test Specimens 
gas backfill, a slight positive gas pressure (less than 6 psi) was maintained within the furnace vessel during the remainder of the test.

Table 4-2

Characterization of Sintered $\mathrm{UO}_{2}$ Pellets

\begin{tabular}{|c|c|c|c|c|c|}
\hline $\begin{array}{c}\text { Batch } \\
\text { Designation }\end{array}$ & $\begin{array}{c}\text { Nominal } \\
\text { Diameter } \\
\text { (Inches) }\end{array}$ & $\begin{array}{l}\text { Nominal } \\
\text { Height } \\
\text { (Inches) }\end{array}$ & $\begin{array}{c}\text { Theoretical } \\
\text { Density \% } \\
\pm 0.2\end{array}$ & $\begin{array}{l}\text { Oxygen to } \\
\text { Uranium } \\
\text { Ratio } \mathrm{O} / \mathrm{U} \\
\end{array}$ & $\begin{array}{c}\text { Average } \\
\text { Grain Size } \\
\text { (Microns) } \\
\end{array}$ \\
\hline B & 0.500 & 0.775 & 94.8 & $\begin{array}{l}2.007^{*} \\
2.009 * *\end{array}$ & 15 \\
\hline C & 0.500 & 0.766 & 92.4 & $\begin{array}{l}2.000^{*} \\
2.004^{* *}\end{array}$ & 14 \\
\hline$E$ & 0.489 & 0.745 & 95.0 & $2.008^{*}$ & $20-35$ \\
\hline F & 0.250 & 0.250 & 97.0 & $\begin{array}{l}2.004^{*} \\
2.003^{* *}\end{array}$ & $6-7$ \\
\hline G & 0.250 & 0.252 & 98.0 & $2.001 * *$ & 18 \\
\hline I & 0.250 & 0.250 & 95.0 & $2.003^{* *}$ & $3-4$ \\
\hline
\end{tabular}

* Thermogravimetric Analysis \pm 0.005

** Coulometric Analysis \pm 0.001

Table 4-3

Typical Spectrographic Analysis Result

Sample No. 19381

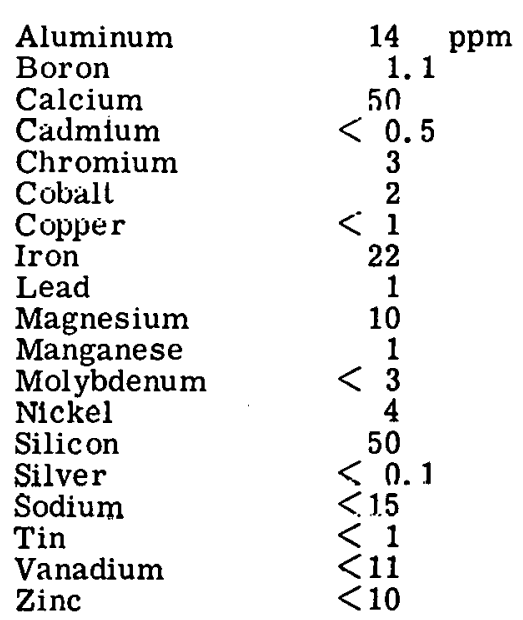


The temperature of the furnace was increased at a constant rate of $50^{\circ} \mathrm{C}$ per minute to the desired test condition. The bottom tungsten plunger was raised to bring the top surface of the $\mathrm{UO}_{2}$ sample.in contact with the top tungsten ram. (No load was applied.) After allowing fifteen minutes to stabilize temperatures within the hot zone of the furnace, an optical cathetometer was used to measure the expanded length of the $\mathrm{UO}_{2}$ sample. The LVDT was calibrated and zeroed and the desired load was applied to the bottom tungsten plunger. The deformation of $\mathrm{UO}_{2} \mathrm{sample}$ (the millivolt output of the LVDT-amplifier) was recorded continuously as a function of time. The shape of the plot was typical of a plastic material subjected to a compressive force. After the initial elastic compression, the deformation rate decreased until a minimum or constant rate was obtained. Depending upon the test conditions, three to ten hours were required to reach a constant creep rate.

The creep rate for each test was calculated using the formula

$$
\dot{\epsilon}=\frac{\Delta \mathrm{L} / \mathrm{t}}{\mathrm{L}}
$$

where. $\quad \dot{\epsilon}=$ steady-state creep rate (in./in./hour)

$\mathrm{L}=$ original sample length at test temperature

$\Delta \mathrm{L}=$ change in sample length after time $t$

$\mathrm{t}=$ time (hours)

The value of $\Delta \mathrm{L} / \mathrm{t}$ was obtained directly from the linear portion of LVDT - amplifier plot.

The furnace temperature was monitored throughout the test with a tungsten - $5 \%$ rhcnium versus tungsten $-26 \%$ rhenium thermocouple junction touching the side of the test pellet.

At the completion of the test, the hydraulic load was removed from the samplc and the furnace was allowed to cool at approximately $50^{\circ} \mathrm{C}$ per mimute to room tempcrature. Measurements were made on the samples to characterize the deformed shapes. The parallelness of the top and bottom of the pellets was measured to establish that in all tests the loading was always uniaxial compression.

A large number of these test pellets were metallographically prepared to measure the post-test grain size and to observe any other microstructural changes. $O / M$ ratio analyses were performed on a number of samples after testing to ensure that the stoichiometry of the test specimens was maintained.

An analysis of the uncertainties in the experimental apparatus and technique is presented in Appendix A. 


\section{EXPERIMENTAL DATA AND DISCUSSION OF RESULTS}

\subsection{Creep of $\mathrm{UO}_{2}$ as a Function of Temperature, Stress, Grain Size and Density}

The purpose of this experiment was to measure the creep behavior of stoichiometric uranium dioxide. During the fabrication of the test specimens, emphasis was placed on obtaining microstructures having homogeneous grain size and porosity distribution. The microstructures of typical "as-fabricated" pellets are shown in Figure 4-4 through Figure 4-6, and physical properties are described in Table 4-2. The initial step in the evaluation of the experimental data was to establish the trends in the creep behavior of the $\mathrm{UO}_{2}$ as a function of material density, grain size, stress and temperature. Forms of the Arrhenius equation, modified to incorporate theoretical descriptions of creep mechanisms were compared with the raw data. In general, the correlation was excellent for measurements of this type, and from the experimental data equation (1) of Section III was derived to describe the creep response of $\mathrm{UO}_{2}$. This expression is valid within the range of experimental conditions and describes within $\pm 32 \%$ the actual experimental results with a $90 \%$ confidence level. The derivation and a discussion of this confidence interval are included in Appendix $B$ along with the experimental data points. The expression for creep is an empirical equation which describes the response of $\mathrm{UO}_{2}$ only over the range of parameters investigated. Extrapolation to conditions other than those observed here should be done with caution. For example, as density approaches $90.45 \%$ of theoretical the calculated creep rates become extremely large. This is not an accurate description of the true behavior of the $\mathrm{UO}_{2}$, and the equation breaks down as an estimator of the creep rate.

The relationship between equation (1) and normalized experimental data is shown in Figures 5-1, 5-2, and 5-3. The three graphs describe the creep response of 14 microns grain size $\mathrm{UO}_{2}$ at three different densities $(97,05$, and $92 \%$ TD respectively). The temperature varied from 1450 to $1750^{\circ} \mathrm{C}$. The plots were gencrated from equation (1), and the data points were normalized using the procedure described in Appendix D.* The correlation between the data and the graphical representation of equation (1) was found to be very satisfactory. This equation describes the creep behavior of $\mathrm{UO}_{2}$ to be the sum of two terms. The relative contribution of each of these terms to the total creep rate is determined by the values assigned to the variables in the equation. Where the applied stress is low (1000 - $3000 \mathrm{psi})$ and material grain size is small (4-12 microns), the calculated creep rate is essentially determined by the first of these two terms. With increasing stress and grain size, the contribution of the second term becomes more important and eventually dominates. Between these two extremes there is a large transition region in which both terms contribute nearly equally. This behavior exhibited by the $\mathrm{UO}_{2}$ indicates that gradual and continuous changes occur in the mechanisms controlling the creep process.

\subsection{EFFECT OF DENSITY ON THE CREEP OF $\mathrm{UO}_{2}$}

Density decreases (increasing porosity) resulted in increased creep rates. This behavior is shown in Figure 5-4 where the creep response predicted by equation (1) for 92, 95, and 97\% TD material is plotted. The differences between the creep rates remained fairly uniform for all values of stress. In Figure 5-5 the creep rate is plotted as a function of density for constant

*The normalizing technique was intended to correct for small variations in the actual test parameters used to obtain the experimental data and to make graphical comparisons of the data and equation (1) more meaningful. 


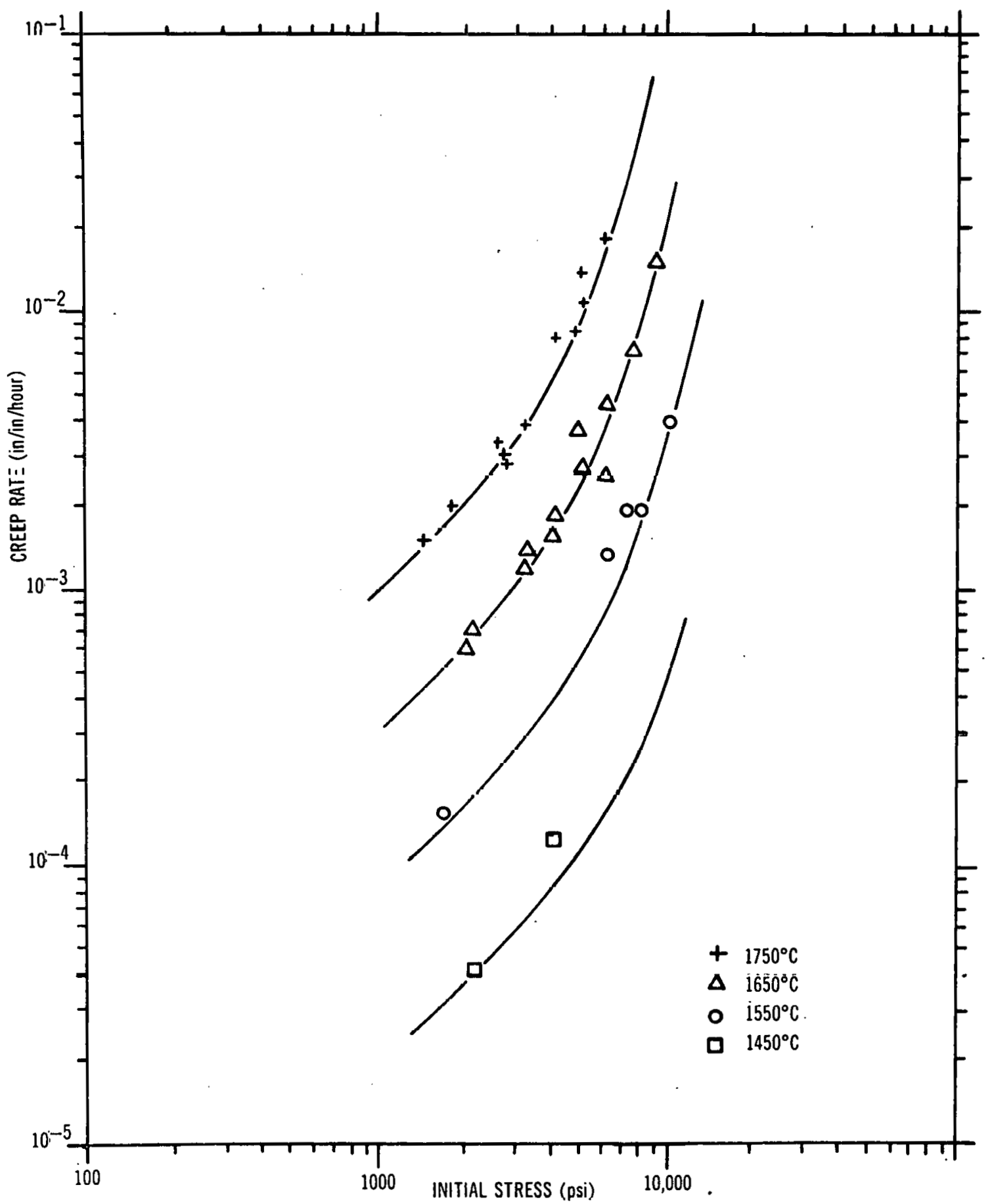

Figure 5-1. Comparison of Normalized Data with Calculated Creep Rates for $97 \%$ TD, 14 Micron $\mathrm{UO}_{2}$ 


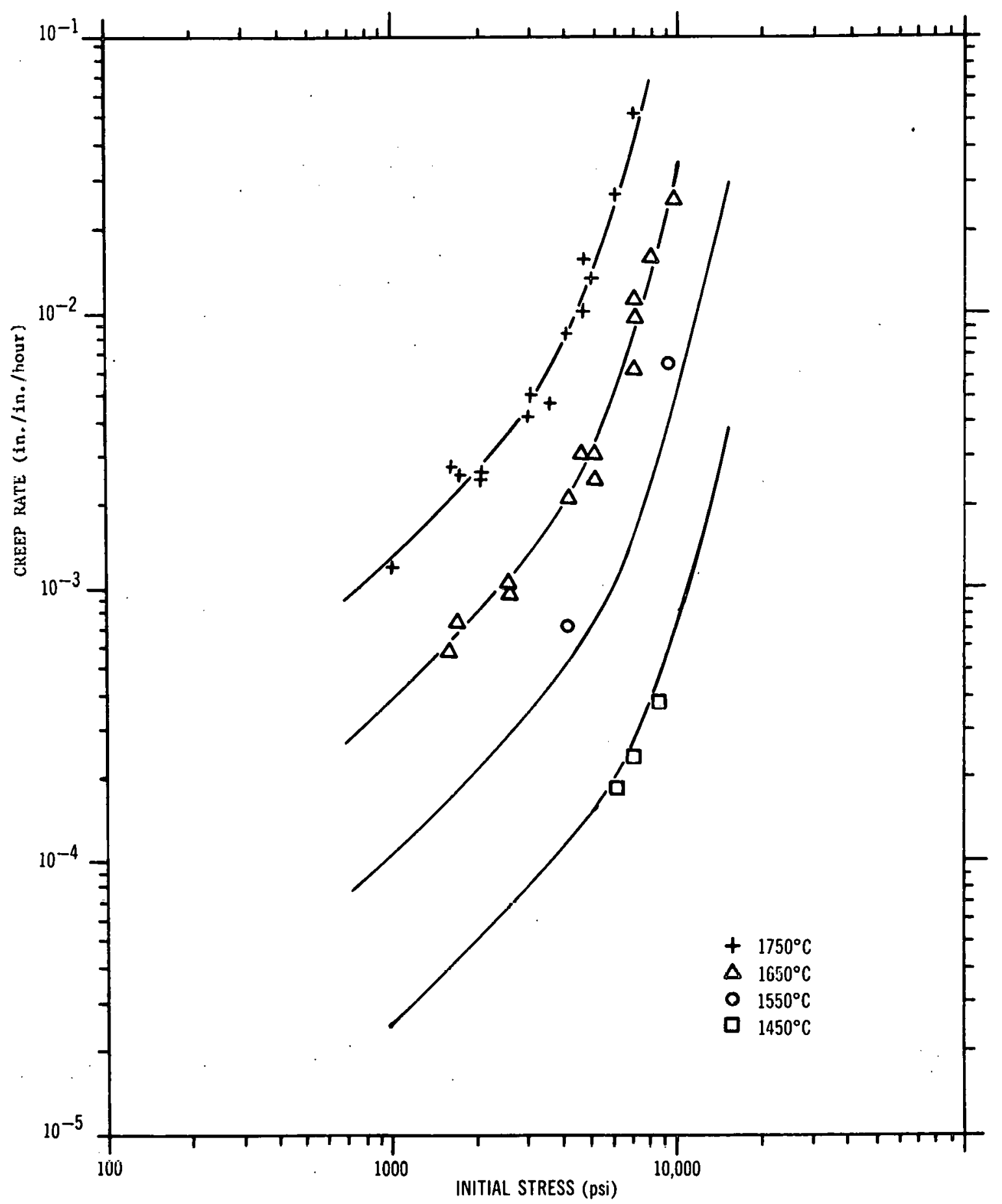

Figure 5-2. Comparison of Normalized Data with Calculated Creep Rates for $05 \%$ TD, 14 Micron $\mathrm{UO}_{2}$ 


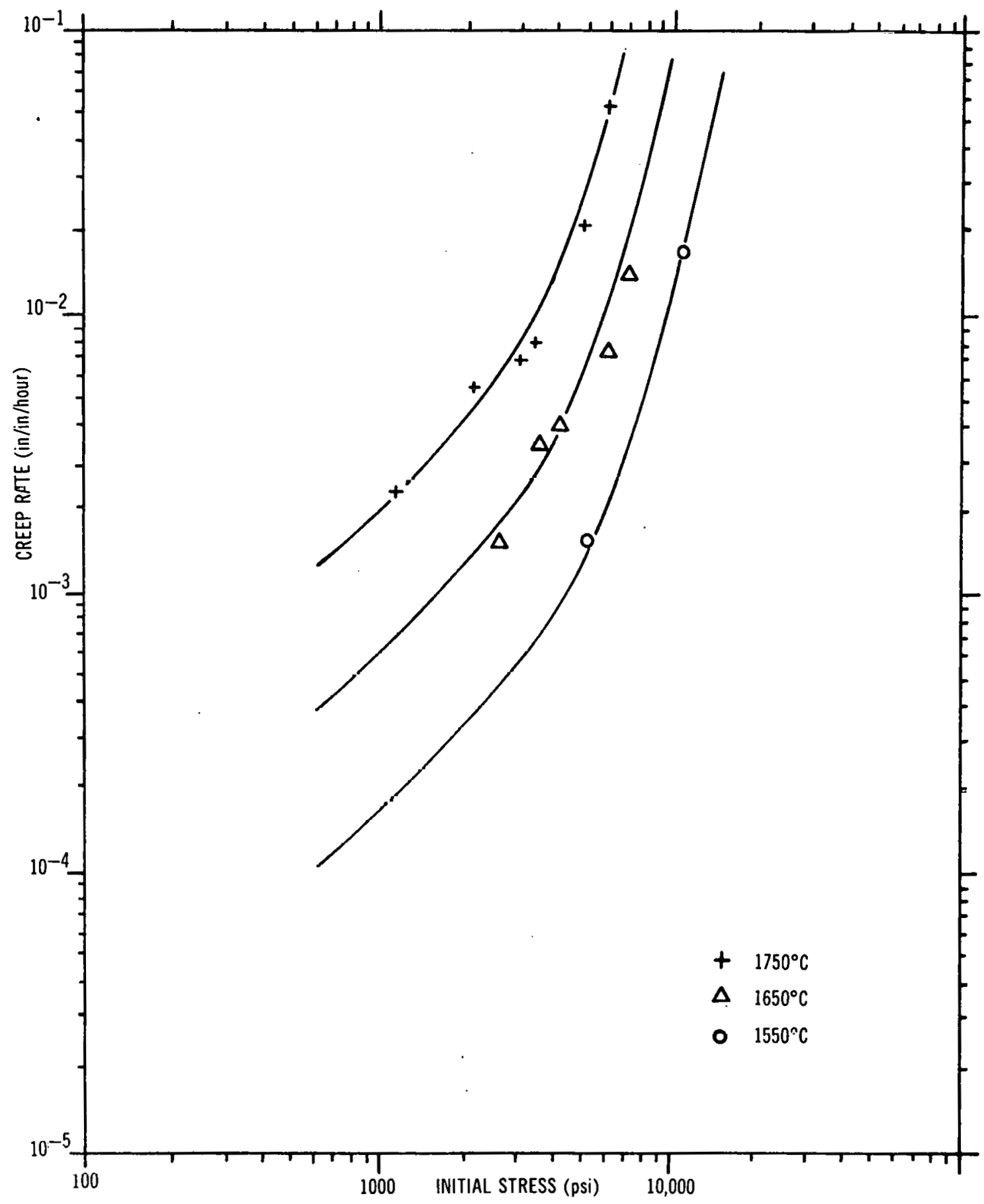

Figure 5-3. Comparison of Normalized Data with Calculated Creep Rates for $92 \%$ TD, 14 Micron $\mathrm{UO}_{2}$ 


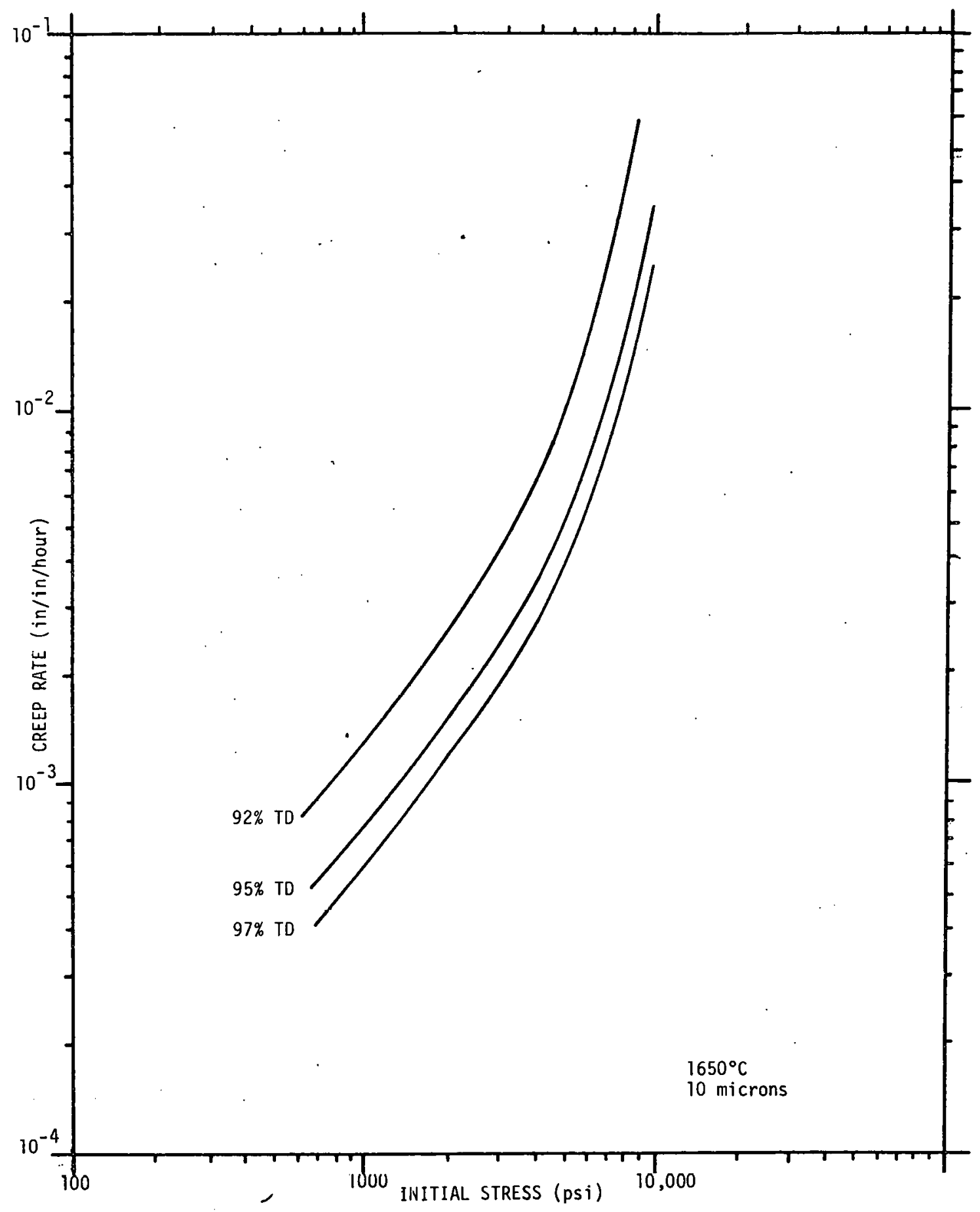

Flgure 5-4. Effect of Densily un Creep Rale of $\mathrm{UO}_{2}$ 


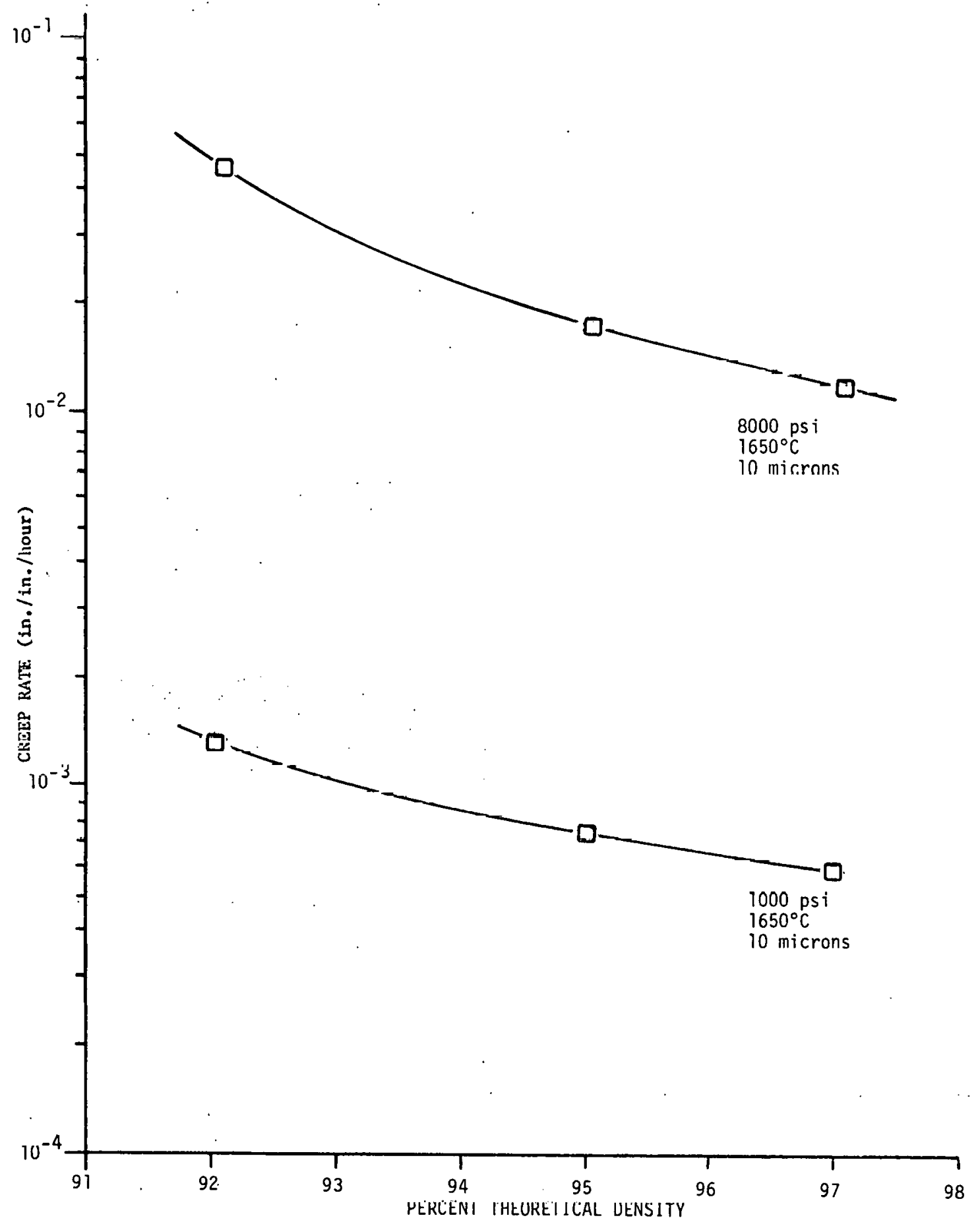

Figure 5-5. Creep Rate as a Function of Density at 1000 and 8000 psi 
stress values of 1000 and $8000 \mathrm{psi}$, and illustrates that density variations have a similar effect at both high and low stress.

Armstrong, et al ${ }^{(9)}$ observed grain boundary sliding in the deformation of $\mathrm{UO}_{2}$ and it was reported that the rate of deformation was directly related to the amount of porosity located in the grain boundaries. The findings of this investigation agree with Armstrong's results. The contribution of grain boundary sliding would be expected to be enhanced by grain boundary porosity and increase the overall creep rate for all values of stress.

\subsection{EFFECT OF GRAIN SIZE ON CREEP RATE OF $\mathrm{UO}_{2}$}

The creep rates of specimens at low applied stress were observed to be inversely proportional to the grain size squared and directly proportional to stress $\left(\dot{\epsilon} \propto \frac{\sigma}{\mathrm{G}^{2}}\right)$. For large stress values, no correlation between grain size and deformation rate was found. In Figure 5-6, equation (1) is plotted for four different grain size values. For relatively small stresses, the creep rates for 7 micron and 25 micron materials differ by an order of magnitude. At 10,000 psi this difference becomes almost negligible.

The data for 1000 psi in Figure 5-6 is plotted again in Figure 5-7. This graph shows that at a constant stress the creep rate decreases with increasing grain size. This type of material behavior is predicted for a diffusional or Nabarro-Herring $(2,3)$ creep mechanism. This prediction of diffusional creep is further substantiated by the agreement between the activation energy necessary for creep ( $90 \mathrm{Kcal} / \mathrm{mole}$ ) at low stress and the activation energy required for the diffusion of uranium atom in $\mathrm{UO}_{2}(70$ to $108 \mathrm{Kcal} / \mathrm{mole}) .(11-13)$ While the activation energy for creep does not define the specific mechanism of deformation, it does show that a strong correlation exists between diffusion and the mechanism of creep at low stress.

\subsection{METALLOGRAPHIC OBSERVATIONS OF STRAINED UO ${ }_{2}$ SAMPLES}

A large number of the $\mathrm{UO}_{2}$ test samples were metallographically examined. In many of these samples an increase in the average grain size was noted. (See Appendix C.) These posttest grain sizes were measured and used in the analysis of the data. Examination of numerous microstructures did not reveal any evidence of grain boundary sliding or grain boundary separation. A number of samples, however, strained under high compressive stresses did show high concentrations of etch pits within the grains. An example of the observed microstructure is shown in Figure 5-8. In general, the etch pits are consistent in shape and orientation within any one grain. The pits in highly strained material may be the traces of dislocation movements within the crystal lattice. The concentration of these etch pits increased with the grain size of the material and the stress at which the deformation occurred. Figure 5-9 shows the typical posttest microstructure of a small 10 micron grain size material tested at $3700 \mathrm{psi}$. In this case, the occurrence of etch pits in the grains is rare, possibly indicating that the grain boundaries rather than crystal lattice were primarily associated with deformation of the material.

The creep rates at high stress values ( $\sim 8000 \mathrm{psi}$ ) were found to be proportional to the stress raised to the 4.5 power $\left(\dot{\epsilon} \propto \sigma^{4.5}\right)$. Weertman ${ }^{(4)}$ proposed that for the face-centered-cubic structure of $\mathrm{UO}_{2}$ this type of behavior would result when dislocation climb allowed dislocations to surmount barriers which normally restrict their motion. Such a mechanism is strongly dependent 


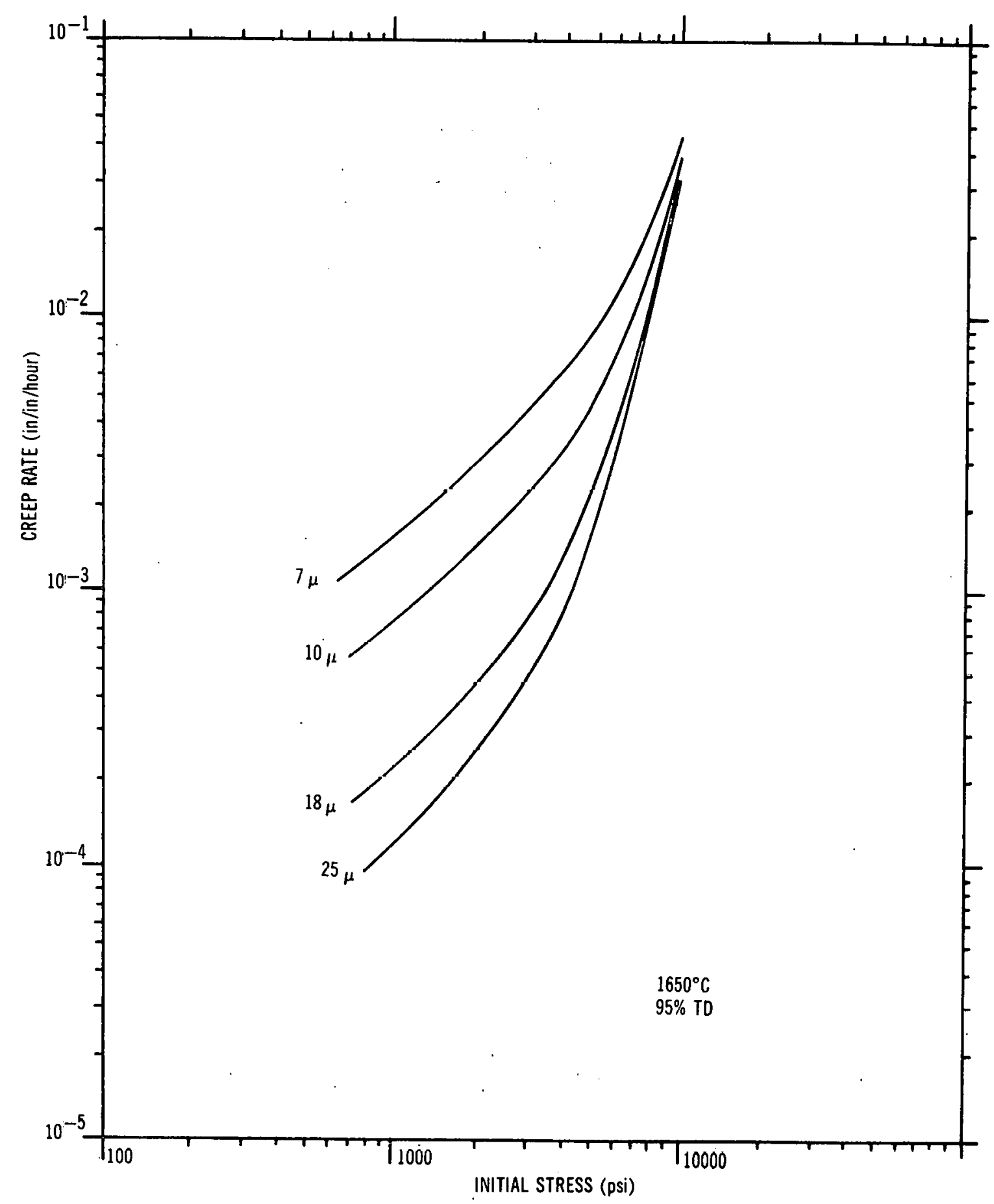

Figure 5-6. Effect of Grain Size on Creep Rate of $\mathrm{UO}_{2}$ 


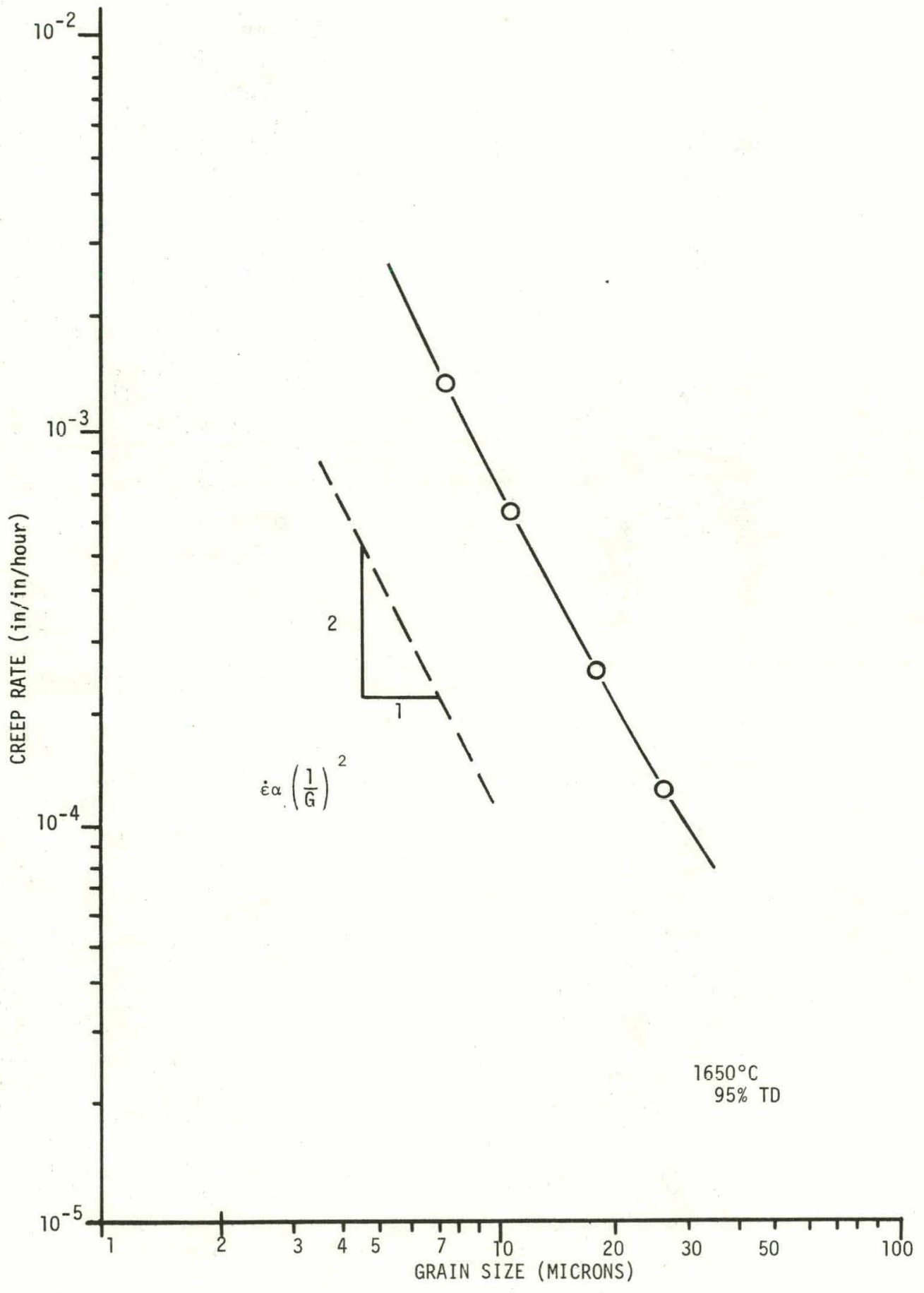

Figure 5-7. Creep Rate as a Function of Grain Size at 1000 psi 


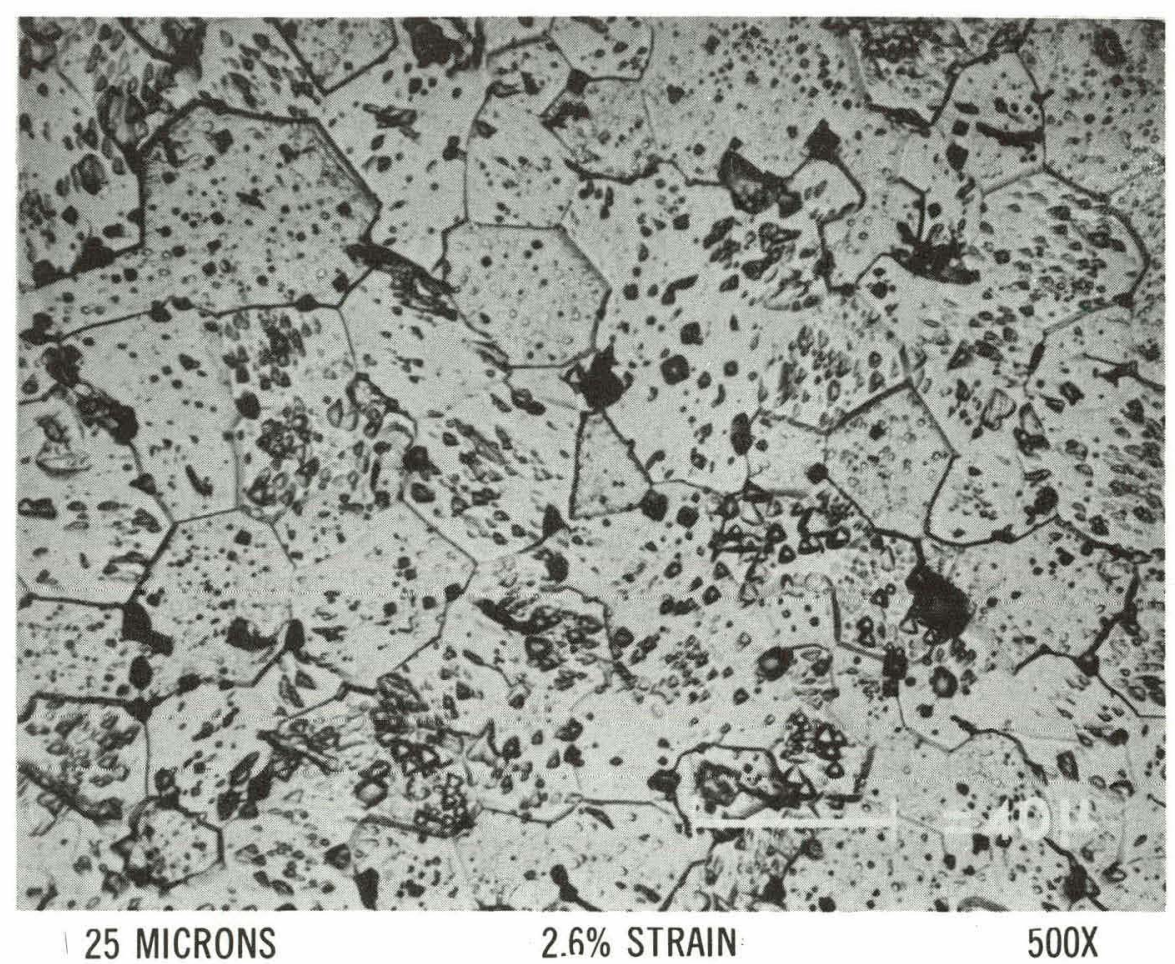

Figure 5-8. Microstructure of $\mathrm{UO}_{2}$ Sample Tested at $1750^{\circ} \mathrm{C}$ and $5000 \mathrm{psi}$

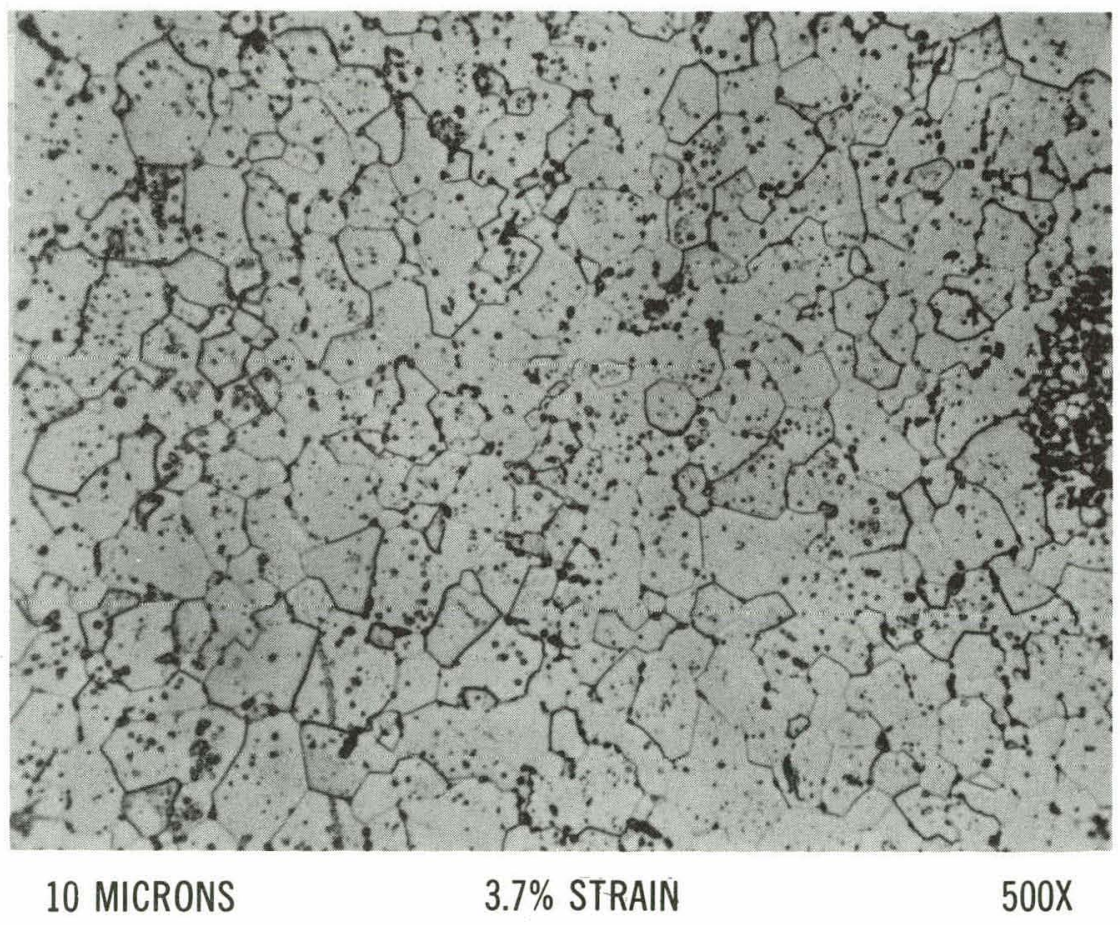

Figure 5-9. Microstructure of $\mathrm{UO}_{2}$ Sample Tested at $1750^{\circ} \mathrm{C}$ and $3700 \mathrm{ps} 1$ 
on the diffusion of atoms and vacancies within the crystal lattice to the area of the pinned dislocation. However, the activation energy obtained for high stress conditions $(132 \mathrm{Kcal} / \mathrm{mole})$ is considerably larger than the activation energy required for uranium diffusion in $\mathrm{UO}_{2}(70-108$ $\mathrm{Kcal} / \mathrm{mole})$. (11-13) This comparison of data suggests that the reported diffusion activation energy values for $\mathrm{UO}_{2}$ are strongly influenced by grain boundary effects." For typical materials, the amount of energy required for lattice diffusion $\left(Q_{L A T}\right)$ is greater than that necessary for grain boundary diffusion $\left(Q_{G B}\right)$. In the few systems where both values have been determined, their relative values have been

$$
Q_{\text {VOL }}: Q_{G B} \cong 4: 3 \text { or } 4: 2
$$

The ratio of activation energies in equation (1) $(90$ and $132 \mathrm{Kcal} / \mathrm{mole}$ ) falls between these two values. This result further supports the idea the creep in $\mathrm{UO}_{2}$ results from grain boundary and lattice diffusion. The mechanism which dominates the deformation is determined by the temperature, stress, and grain size of the material.

\section{5 COMPARISON OF EXPERIMENTAL RESULTS WITH PREVIOUSLY REPORTED CREEP DATA ON UO 2}

A graphical comparison of equation (1) with previously reported creep data has shown the agreement to be very satisfactory. In Figure 5-10, the expression

$$
\dot{\epsilon}=2 \times 10^{4} \sigma^{1.3} \exp (-91,000 / \mathrm{RT})
$$

suggested by Armstrong, et al ${ }^{(9)}$ for 6 micron, $96 \% \mathrm{TD} \cup \mathrm{UO}_{2}$ at $1400^{\circ} \mathrm{C}$ has been plotted. In Figure 5-11, the data reported by Wolfe and Kaufman ${ }^{(6)}$ and Poteat and Yust ${ }^{(10)}$ is given. In each of these figures, curves generated from equation (1) using the test conditions reported by the other experimenters are presented. In general, the data is within a factor of 2 or 3 of the values calculated from equation (1). 


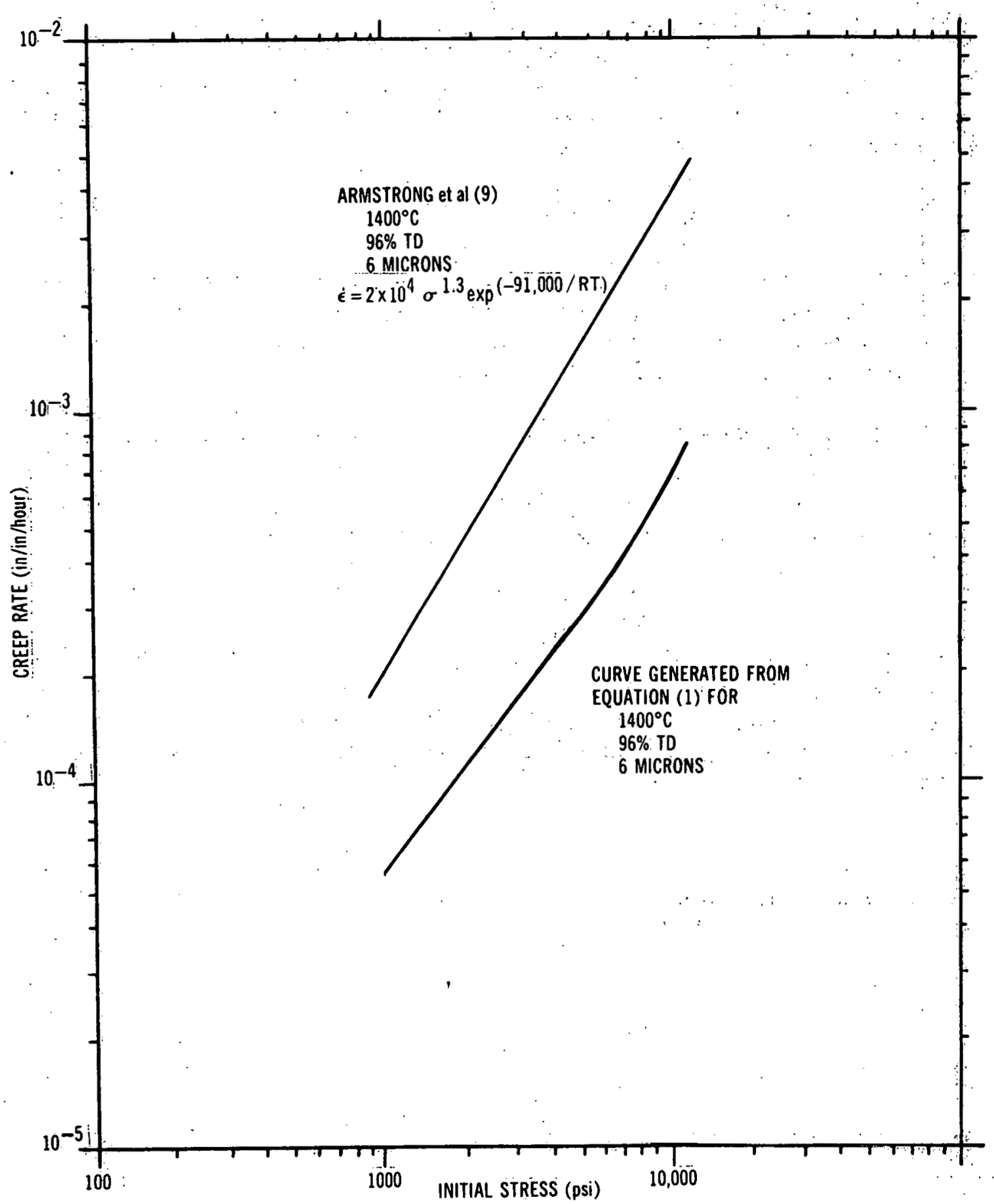

Figure 5-10. Comparison of Results with Bend Test Creep Data of $\mathrm{UO}_{2}$ 


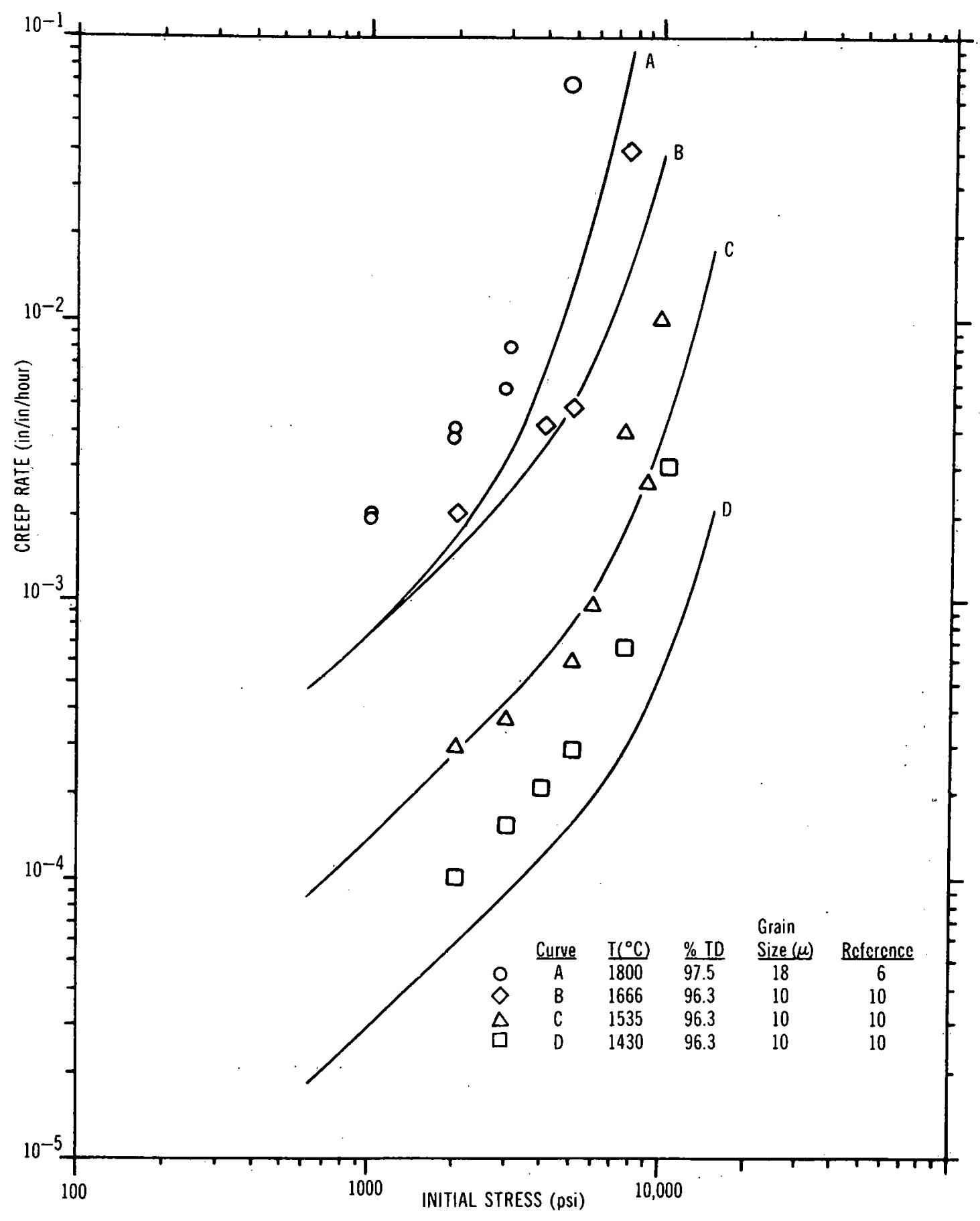

Figure 5-11. Comparison of Experimental Results with Previously Reported Compression Creep Data of $\mathrm{UO}_{2}$ 


\section{APPENDIX A}

\section{PRECISION OF EXPERIMENTAL TECHNIQUE}

The uncertainty in the measured creep rates is the composite effect of all the possible random errors in the experimental technique. The propagation of these errors in a typical test can significantly affect the experimental result. Discussed below are each of the major test variables, the uncertainties in these variables, and their combined effect on the precision of the experimental technique.

\section{A. Temperature}

A calibrated tungsten - $5 \%$ rhenium versus tungsten $-26 \%$ rhenium thermocouple was used to measure the test temperature. The thermocouple was touching the side of the $\mathrm{UO}_{2}$ test specimen, and the measurements were accurate within $\pm 1.0 \%$ of the absolute temperature. At $1700^{\circ} \mathrm{C}$ this results in a $\pm 17^{\circ} \mathrm{C}$ uncertainty in the temperature data.

The furnace provided a stable and isothermal heat zone. The drift in temperature during a typical test was less than $4^{\circ} \mathrm{C}$. A pellet containing black-body holes was used to check for temperature gradients. Within experimental error of a calibrated optical pyrometer $\left( \pm 20^{\circ} \mathrm{C}\right)$ no significant axial or radial temperature variations were observed.

\section{B. Comprcssive Load}

Drift in the hydraulic load applying the compressive force was held constant within \pm 2 psig. On a 0.250 inch diameter pellet under a 1000 psi compressive stress this produces an uncertainty in the load of $\pm 4 \%$. At larger stresses the errors become smaller and insignificant.

The test samples typically deformed into a barrel shape with a resulting increase in the maximum cross-section area. In Figure A-1 the maximum change in the area of a number of test pellets is plotted as a function of percent strain. In all but a few tests, the change in area and the resulting uncertainty in the calculated stress was less than $4 \%$. This change in area was not considered in calculating the applied stress. The original cross-section area was used to calculate all stress values.

Parallelism between the top and bottom surfaces of the tungsten plungers was measured to be within 0.0015 inches. Consequently, the applied load was the true compressive load on the sample and the contribution of torque or shear forces was negligible.

\section{c. GRAIN SIZE}

A linear intercept method was used to measure the average grain size on the "as-fabricated" and tested $\mathrm{UO}_{2}$ test pellets. ${ }^{(14)}$ The microstructures were reasonably uniform in grain size and distribution, and the estimated values were considered to be within $10 \%$ of the true average grain size. 


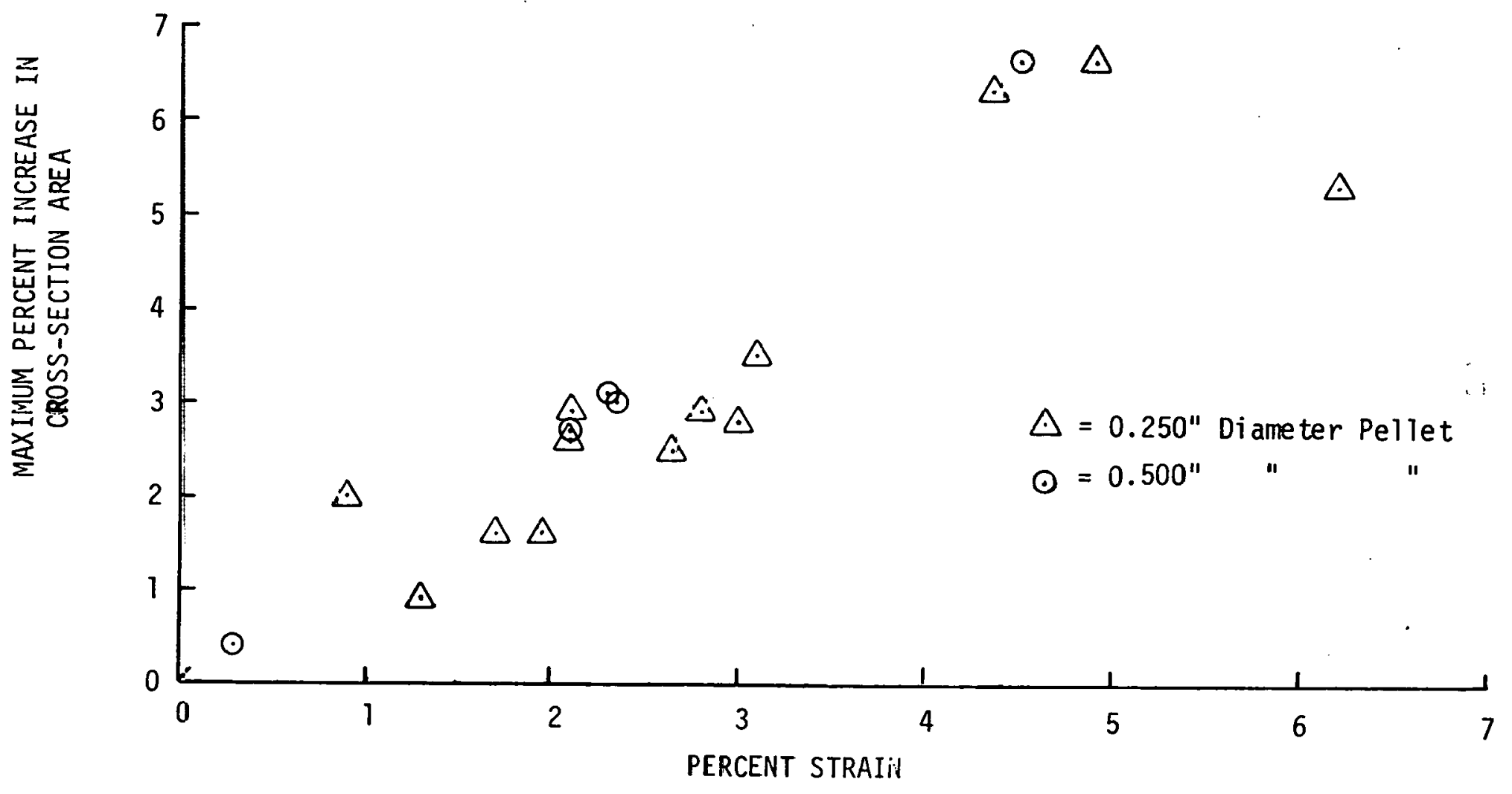

Figure A-1. Increase in the Cross Section Area versus the Fercent Strain in the Sample Length 


\section{DENSITY}

Density measurements were made on a number of pellets before and after testing by both water and mercury immersion techniques. Changes in the density of strained $\mathrm{UO}_{2}$ samples were small and less than $0.2 \%$ of theoretical.

E. CUMULATIVE EFFECT OF UNCERTAINTIES ON THE PRECISION OF

EXPERIMENTAL DATA

Random variations or errors in the test parameters had a cumulative effect on the experimental results. The variations of these parameters did not affect the experimental result in an identical manner. Each error had to be weighed according to its importance and influence on the experimental result. In Section 3 , the equation describing creep behavior of $\mathrm{UO}_{2}$ effectively weights each of the test variables. This equation was used to calculate creep rates where the errors were allowed to accumulate to maximize or minimize the result. The calculated creep rates were found to vary up to $\pm 50 \%$. This, however, represents the worst possible combination of experimental errors and the probability of it occurring in a single experimental test was very slight. The test procedure was designed to prevent this type of error buildup. Duplicate tests were made in an attempt to obtain a quantitative measure of the precision of the experimental apparatus. Results of these tests indicated that experimental results were reproducible within $\pm 20 \%$. 


\section{APPENDIX B}

\section{ANALYSIS OF EXPERIMENTAL DATA}

The experimental data obtained during this investigation was a sampling of the actual creep behavior of polycrystalline $\mathrm{UO}_{2}$ for various conditions of temperature, stress, grain size, and density. The trends in this data as a function of the test variables have been described by the equation derived in Section 3. This equation serves as an estimator which predicts the creep behavior of $\mathrm{UO}_{2}$. A data evaluation study was conducted to determine the confidence that can be placed in the estimates provided by this equation. A comparison was made between the experimental data and the calculated creep rates. The estimated test conditions of temperature, stress, grain size, and density were used to obtain the calculated values. The comparison was then made by using the following formula:

$$
\mathrm{X}=\frac{\dot{\epsilon}_{\text {exp }}-\dot{\epsilon}_{\text {cal }}}{\dot{\epsilon}_{\text {cal }}} 100
$$

where

$$
\begin{aligned}
\mathrm{X} & =\text { the percent difference } \\
\dot{\epsilon}_{\text {cal }} & =\text { calculated creep rate } \\
\dot{\epsilon}_{\text {exp }} & =\text { experimental creep rate }
\end{aligned}
$$

The results are presented in Table B-1 along with the experimental data. The largest difference between an experimental and calculated creep rate was $45 \%$. Conventional statistical formulas were used to evaluate the distribution of these differences. For the 90 experimental data points, the sample mean $(\bar{X})$ and the standard deviation $\left(S_{X}\right)$ of the differences were $1.1 \%$ and $18.6 \%$ respectively. The positive and negative results were evenly divided (46 positive and 44 negative), and a graph of this data is plotted in Figure B-1. If the distribution shown in this figure is assumed to be normal, the following general statement can be made about the precision of the equation as an estimator of experimental results:

Using the experimental technique described previously, there is $90 \%$ confidence that the percent difference between experimental and calculated creep rates $(\mathrm{X})$ will fall within interval $(-32 \% \leq \mathrm{X} \leq+32 \%)$.

This comparison may be carried one step further and restated as:

$$
\dot{\epsilon}_{\text {exp }}=\dot{\epsilon}_{\text {cal }} \pm 32 \% \quad \dot{\epsilon}_{\text {cal }}(90 \% \text { confidence }) .
$$

This level of confidence is valid only where the variables used in the calculations fall within the range of values:

Compressive Stress
Temperature
Density
Grain Size

Compressive Stress

Density

Grain Size

$$
\begin{aligned}
1000 & -15,000 \mathrm{psi} \\
1440 & -1760^{\circ} \mathrm{C} \\
92.0 & -98.0 \% \text { Theoretical. } \\
4 & -35 \text { microns }
\end{aligned}
$$


Table B-1. Comparison of Experimental Data and Calculated Creep Rates

\begin{tabular}{|c|c|c|c|c|c|c|c|c|}
\hline $\begin{array}{l}\text { It51 } \\
\text { NU. }\end{array}$ & $\begin{array}{l}\text { SIRESS } \\
\text { (PSI) }\end{array}$ & 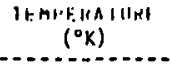 & ${ }^{2}$ & 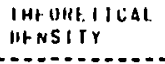 & $\begin{array}{l}\text { MFAIN SILK } \\
\text { IMICRUNS) }\end{array}$ & $\begin{array}{l}\text { EXPEHIMLNIAL } \\
\text { CHEER KAIE }\end{array}$ & $\begin{array}{l}\text { CALCULAIEU } \\
\text { CRFIP RAIE } \\
\end{array}$ & $\begin{array}{l}\text { Wo WUiERENCE } \\
\text { IN CREEP RAILS }\end{array}$ \\
\hline 54. & 110011. & 21120. & & Y4.A & 17. & $B .53 E-04$ & $9.22 E-04$ & -9.62 \\
\hline 81. & 1130. & $2+2 y$. & & 92.4 & 17. & $1.65 t-03$ & $1.67 t-03$ & -1.25 \\
\hline 41 & 14011. & 21824. & & 97.2 & 10. & $3.10 t:-03$ & $2.88 E-03$ & 7.64 \\
\hline 61. & bs>b. & $192 \mathrm{~J}$. & & 04.4 & 17. & $3.99 t-04$ & $4.54 t-04$ & $-12.1 \mathrm{~s}$ \\
\hline 74. & 1023. & 2421. & & 93.0 & 20. & $1.30 t=03$ & 1. USE-U3 & 25.66 \\
\hline 101. & 1660. & 1in2.4. & & 47.7 & B. & $6.20 t-04$ & $7.57 E-04$ & 8.38 \\
\hline 84. & 1075 & $192 \mathrm{H}$. & & 95.2 & s. & 5.471 .03 & $3.40 E-03$ & 8.78 \\
\hline Az. & 1100 & 2"2. & & 95.0 & 7. & $9.3 \cap t=03$ & $8.41 E-0 S$ & 12.93 \\
\hline 70. & 11411. & $2117 \mathrm{H}$. & & 45.7 & B. & $8.50 t=03$ & 7.0SE-03 & 20.90 \\
\hline 90, & 1773. & 2012. & & $y / .5$ & 7. & $0.60 \mathrm{~L}-0 \mathrm{~S}$ & $5.98 E-03$ & 10,35 \\
\hline 48 & 2050. & 1920. & & 97.5 & 10. & $1.10 t-03$ & $1.16 E-03$ & -5.00 \\
\hline 60. & 2070. & 20.36. & & 94.8 & 18. & $1.82 t-03$ & $2.11 E=03$ & -13.86 \\
\hline 89. & 7us. & $14.3 \%$. & & 97.11 & 6. & A. $23 t-0 s$ & $3.94 t-03$ & 1.18 \\
\hline 64. & 2073. & 2024. & & 95.0 & 35. & $3.50 t=04$ & $0.04 E-04$ & -8.97 \\
\hline 95. & 2080. & 1731 & ' & 47.0 & 1. & $5.84 t=04$ & B.HIt- 44 & 11.51 \\
\hline 68. & 2.100 & $2112 \%$ & & 92.4 & 17. & $0.47 t-03$ & $S . J 1 E-0 S$ & 19.91 \\
\hline 65. & 2540. & 19.31. & & y5.0 & 20. & $5.00 t=04$ & $0.16 E-04$ & -5.89 \\
\hline 71. & 2570. & 1420. & & 92.4 & 17. & $1.12 t-03$ & $1.2 \forall E-03$ & -12.43 \\
\hline 84. & 2.570. & $1 \times 29$. & & 45.7 & 1. & $3.75 t-03$ & $4.34 E-103$ & -13.50 \\
\hline Bo. & 2575 & 7011. & & 97.5 & 9. & $0.40 \mathrm{E}=0 \mathrm{~J}$ & B.SBE-US & 19.53 \\
\hline 4s. & 2700 & 21124 & & 9.7 .4 & 13. & $3.94 t=03$ & J.SJE-US & 0.32 \\
\hline $5 \%$ & $\because .150$. & 2635. & & 47.3 & 12. & $4.111 t-133$ & $4.42 t-35$ & -7.28 \\
\hline $7 \%$ & 2970. & 2115. & & 94.9. & 9. & $0.0 O E-U 3$ & h. H9k-US & $-1 \mathrm{n} .0 \mathrm{~s}$ \\
\hline 31. & 3025. & $2112 \%$ & & 94.8 & 10. & $2.74 L=03$ & $J+17 t-03$ & -1.3 .53 \\
\hline 36. & 30811. & $70 ? 1$. & & 92.4 & 37. & S.S7t-0S & $n, J 9 t-b s$ & -16.01 \\
\hline
\end{tabular}


Table B-1. Comparison of Experimental Data and Calculated Creep Rates (Continued)

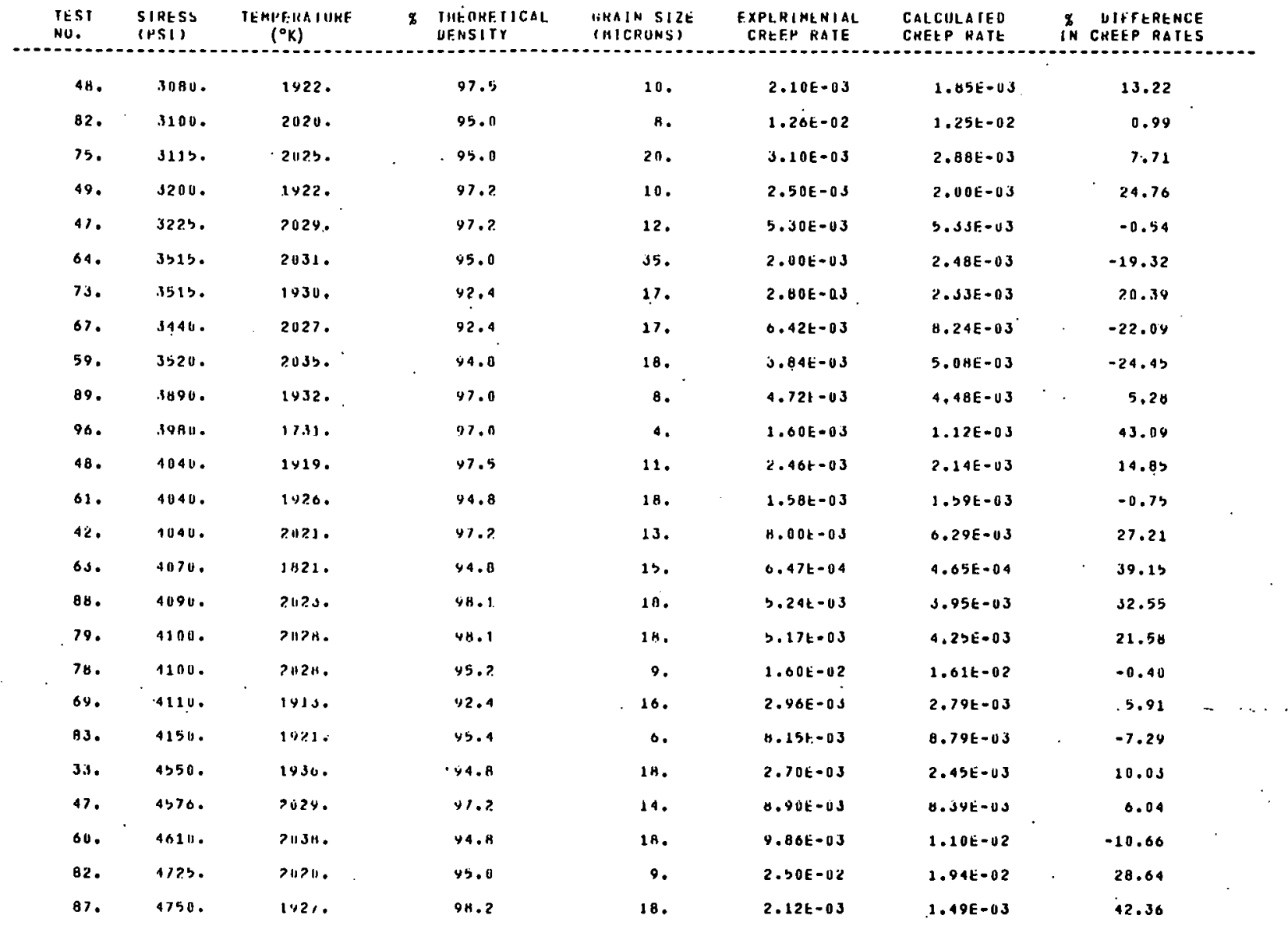


Table B-1. Comparison of Experimental Data and Calculated Creep Rates (Continued)

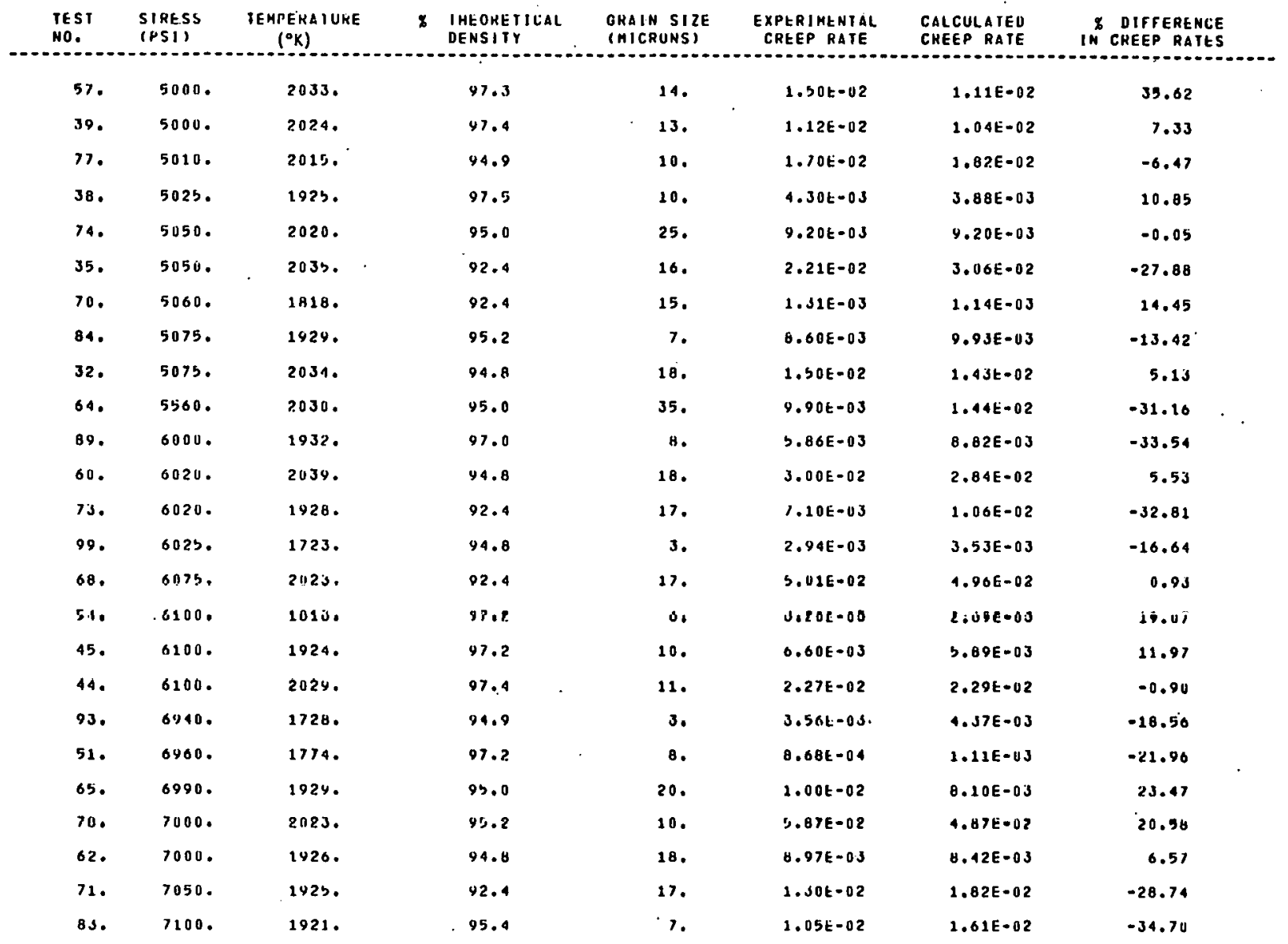


Table B-1. Comparison of Experimental Data and Calculated Creep Rates (Continued)

\begin{tabular}{|c|c|c|c|c|c|c|c|}
\hline $\begin{array}{l}\text { IES I } \\
\text { NO. }\end{array}$ & $\begin{array}{l}\text { SIRESS } \\
\text { (PSI) }\end{array}$ & $\begin{array}{l}\text { If.MFFKA TUKE } \\
\left({ }^{\circ} \mathrm{K}\right)\end{array}$ & $\begin{array}{l}\text { \& IHEUKFIICAI. } \\
\text { IFNSITY }\end{array}$ & $\begin{array}{l}\text { GHAIN SIZE } \\
\text { (MICRUNS) }\end{array}$ & $\begin{array}{l}\text { EXPERIMENIAL } \\
\text { CHEEP HATE }\end{array}$ & $\begin{array}{l}\text { CALCULATED } \\
\text { CRETP HATE }\end{array}$ & $\begin{array}{l}\text { \% UIFFERENCE } \\
\text { IN CREEP RATES }\end{array}$ \\
\hline 53. & 7140 & IALS. & 97.2 & 6. & $3.45 E=03$ & $3.37 E-U 3$ & 17.05 \\
\hline 50. & 7150. & 1769. & 96.7 & 8. & $9.49 E-04$ & $1.14 E-03$ & -16.84 \\
\hline 49. & 7475. & 1920. & 97.2 & 11. & $7.83 E-03$ & $8.68 t-03$ & $-9.8 \mathrm{~s}$ \\
\hline 54. & 7940. & $181 \%$ & $97 . ?$ & 7. & $3.46 \mathrm{E}=0 \mathrm{~J}$ & $3.14 E-03$ & 10.23 \\
\hline 62. & sosu. & 1925. & 94.8 & 18. & $1.32 E-U 2$ & $1.42 t-02$ & $6.7 \mathrm{~s}$ \\
\hline 9.1. & Bis fit. & $172 \mathrm{H}$. & 94.9 & 3 & $4,20 E-03$ & $5,54 \mathrm{E}-03$ & -24.13 \\
\hline 40. & Bบ5C. & 1936. & 97.5 & 10. & $2.05 E=02$ & $2,08 E-02$ & -1.26 \\
\hline 73. & 9020. & 2023. & 95.0 & 25. & $1.50 E-01$ & $1.07 E-01$ & 39.83 \\
\hline $4 x$ & 9500. & 1776. & 97.4 & 8. & $1.57 \mathrm{E}-0 \mathrm{~J}$ & $2.12 t-03$ & -25.89 \\
\hline 84. & 2660. & 1ッ2乡. & 45.2 & 8 . & $3.37 t=02$ & $3.95 \mathrm{E}-02$ & -14.76 \\
\hline 41. & 9900. & $176 \%$ & 97.3 & 8. & $1.43 E=03$ & $1.96 E=03$ & -26.10 \\
\hline 54. & 10000 & 1812. & 97.2 & 7. & $5.38 t=03$ & $3.29 E-03$ & 1.71 \\
\hline 70. & 10450. & LHIh. & 92.4 & 14. & $1.40 \mathrm{t}=02$ & $1.30 t-02$ & -8.40 \\
\hline 50. & 1.5100 & 1769 & 96.7 & ค. & $4.10 t-03$ & $2.20 t-03$ & -10.69 \\
\hline 51. & 1s4nu. & $177 \%$ & 97.2 & 8 . & $1.42 t-02$ & 1. $4 J E-U 2$ & -3.42 \\
\hline
\end{tabular}

ARITHHETIC MHAN $=1.11 \%$

Sample Siakdaku veVIaTION= 1H.b\%: 


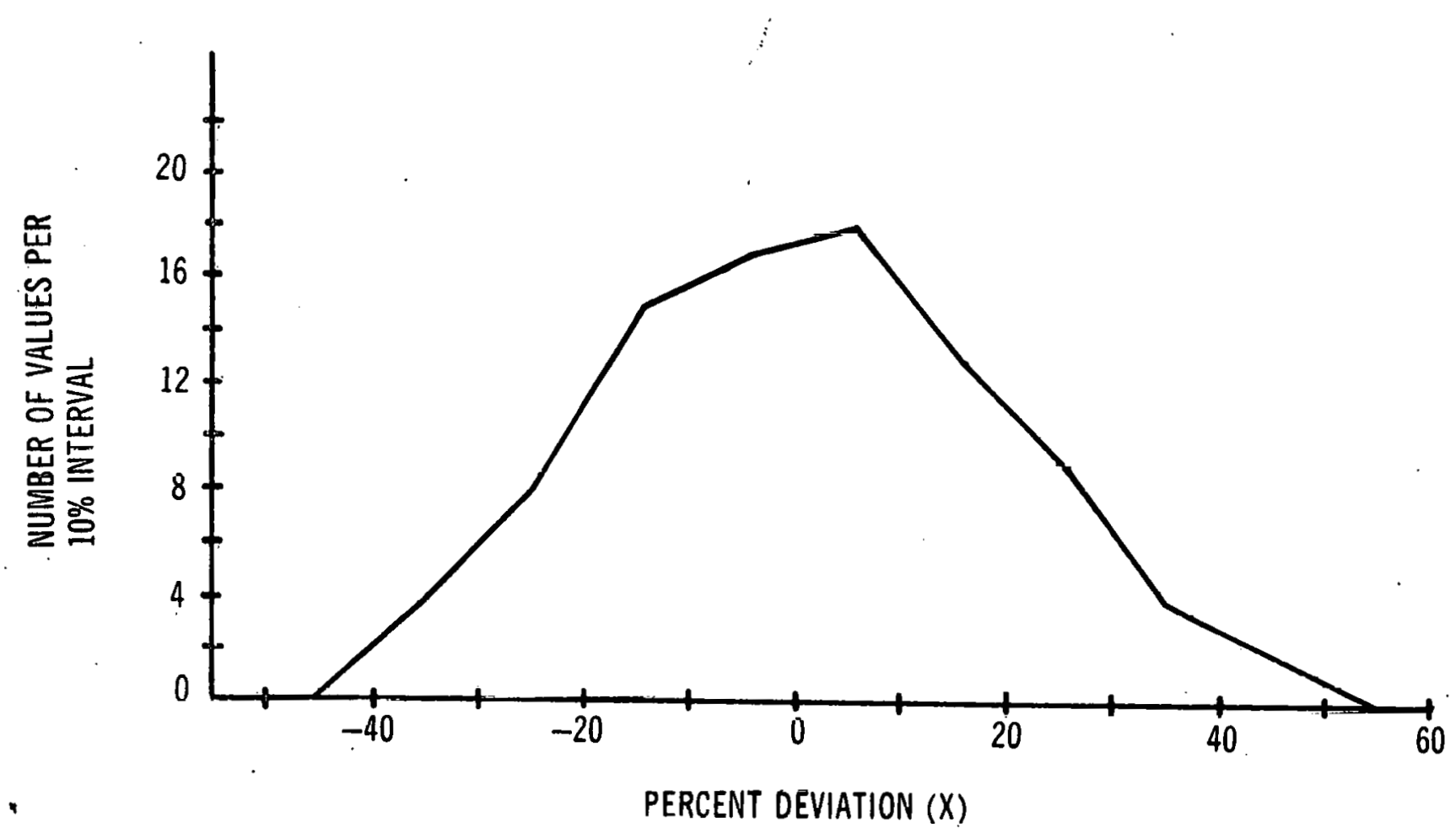

SAMPLE MEAN

$$
\begin{aligned}
& \bar{x}=\frac{\Sigma x}{n} \\
& \bar{x}=1.1 \%
\end{aligned}
$$

SAMPLE STANDARD DEVIATION

$s_{x}=\sqrt{\frac{\Sigma(x \cdot \bar{x})^{2}}{n \cdot \overline{1}}}$

$S_{x}=18.6 \%$

$$
\text { SAMPLE SIZE }(n)=90
$$


The width of the confidence interval indicates the precision of the creep expression as an estimator of the true creep behavior, and it shows the magnitude of the sampling error (e.g. , uncertainty in experimental procedure and apparatus). In Appendix A, an analysis of the experimental technique showed that the precision or reproducibility of experimental data was on the order of $\pm 20 \%$. This suggests that a large portion of the differences found between experimental and calculated creep rates results from uncertainties in the experimental technique. Consequently, the expression in Section 3 may provide a better estimate of the true creep behavior of $\mathrm{UO}_{2}$ than is suggested by the $90 \%$ confidence interval of $\pm 32 \%$. 


\section{APPENDIX C}

\section{GRAIN GROWTH OF UO 2 SAMPLES}

Metallographic inspection of $\mathrm{UO}_{2}$ creep test specimens indicated that changes had occurred in the microstructure during testing. The average grain size increased at a rate greater than anticipated. Since the creep experiments were not originally intended to study this phenomena, the quantitative data is inadequate to thoroughly analyze. It is, however, of interest and worth noting. In Figure C-1, the increase in the grain size of the creep specimens is plotted as a function of time. Data on the grain growth of $\mathrm{UO}_{2}$ is plotted for comparison. MacEwan ${ }^{(16)}$ stated that the mean grain diameter $\mathrm{D}$ (microns) after annealing for $\mathrm{t}$ hours at a temperature $\mathrm{T}\left({ }^{\circ} \mathrm{K}\right.$ ) was given by the equation:

$$
D^{2}-D_{o}^{2}=k_{o} t^{0.8} \exp (-87000 / R T)
$$

where $D_{0}$ and $k_{0}$ are, respectively, the initial grain size and proportionally constant. Ustng this. equation, MacEwan's data was extrapolated to the temperatures of interesit in the creep and plasticity study. In all cases, the increase in the average grain size of samples under compressive loads of 1000 to $12,000 \mathrm{psi}$ was 2 to 3 times that predicted for normal stress free grain growth of the $\mathrm{UO}_{2}$. 


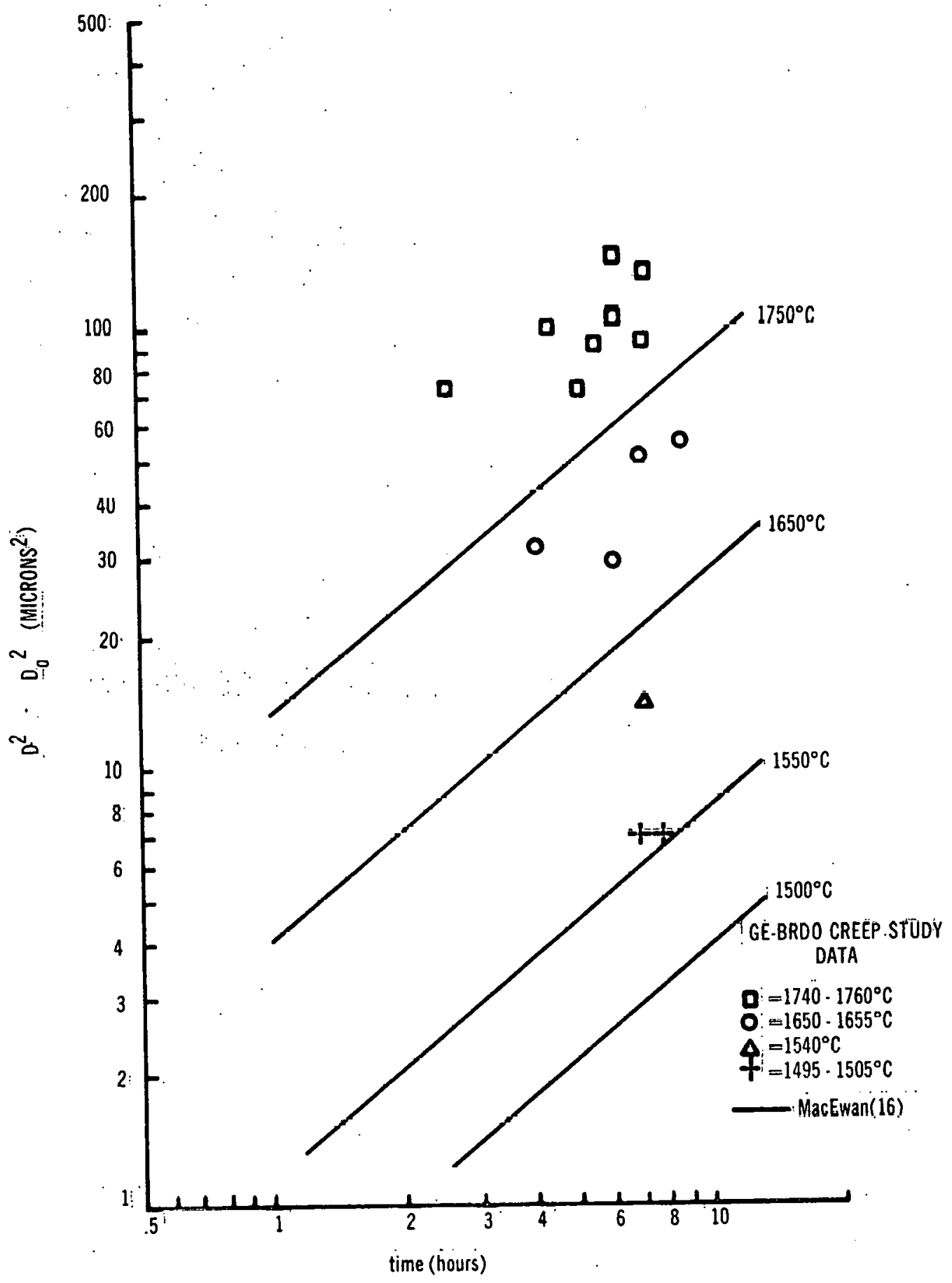

Figure C-1. Increase in Average Grain Size of $\mathrm{UO}_{2}$ as a Function of Time and Temperature 


\title{
APPENDIX D
}

\author{
PROCEDURE FOR NORMALIZING EXPERIMENTAL DATA
}

The experimental data was for the most part grouped about specific values of temperature, density, and grain size. Small variations from these nominal values, however, were present in most of the data. For example, a number of tests were intended to be made at a nominal temperature of $1650^{\circ} \mathrm{C}$. The actual temperatures of these individual tests were anywhere from 1640 to $1660^{\circ} \mathrm{C}$. Similar variations existed in the density and grain size numbers. A graphical presentation of the data in this form made interpretation difficult and had little value. Consequently, experimental data that were grouped about the same nominal values were "normalized" to the same temperature, grain size and density. The technique used to normalize the data is best described by an example:

The following experimentally obtained creep rate is to be normalized to $1750^{\circ} \mathrm{C}, 95 \% \mathrm{TD}$ and 14 microns.

$\begin{array}{ll}\text { T'est No. } & 59 \\ \text { Stress } & 1000 \mathrm{psi} \\ \text { Temperature } & 1753^{\circ} \mathrm{C} \\ \text { Density } & 94.8 \% \mathrm{TD} \\ \text { Grain Size } & 17 \mathrm{microns} \\ \text { Experimental Creep Rate } & -8.33 \times 10^{-4} \mathrm{in.} / \mathrm{in} . / \text { hour } \\ \quad\left(\dot{\epsilon}_{\text {exp })}\right. & \end{array}$

Using the conditions of test no. 59 , the creep rate calculated by equation (1) in Section 3 is

$$
\dot{\epsilon}_{1}=9.22 \times 10^{-4} \text { in. /in./hour }
$$

In a similar manner the creep rate calculated for the desired conditions of $1750^{\circ} \mathrm{C}, 97 \% \mathrm{TD}$, 1000 psi and 14 microns is

$$
\dot{\epsilon}_{2} \equiv 1.27 \times 10^{-3} \text { in. } / 1 \text { n. } / \text { hoür }
$$

Substituting the above values into the following expression, a normalized creep rate $\left(\dot{\epsilon}_{\mathfrak{n}}\right)$ is obtained.

$$
\begin{aligned}
& \frac{\dot{\epsilon}_{\mathrm{n}}}{\dot{\epsilon}_{2}}=\frac{\dot{\epsilon}_{\mathrm{exp}}}{\dot{\epsilon}_{1}} \\
& \frac{\dot{\epsilon}_{\mathrm{n}}}{1.27 \times 10^{-3}}=\frac{8.33 \times 10^{-4}}{9.22 \times 10^{-4}} \\
& \dot{\epsilon}_{\mathrm{n}}=1.14 \times 10^{-3} \mathrm{in.} / \mathrm{in} . / \text { hour }
\end{aligned}
$$


The value of $\dot{\epsilon}_{\mathbf{n}}$ represents the creep rate that would have been obtained had the test been conducted at $1750^{\circ} \mathrm{C}, 95 \% \mathrm{TD}$, and 14 microns rather than at $1753^{\circ} \mathrm{C}, 94.8 \% \mathrm{TD}$ and 17 microns. Normalizing groups of data in the above manner makes the graphical comparison of data from the different tests clearer and more meaningful. 


\section{ACKNOWLEDGMENTS}

The authors are grateful to W. E. Baily for his direction and encouragement during the course of this investigation; G. R. Hull for his assistance in the computer analysis of the data; Dr. G. F. Melde for the helpful discussions during the preparation of this document; and R. L. Bertolotti for the design of the test apparatus. 


\section{REFERENCES}

1. Nadeau, J. S., "The Strength of Non-Stoichiometric Oxides," General Electric Research and Development Center, June 1967 (67-C-243), p. 9.

2. Nabarro, F. R. N., "Deformation of Crystals by the Motion of Single Ions," Rep. Conf. Strength of Solids, London, Physical Society, 1948, p. 75.

3. Herring, C., J. Appl. Phys., 21, 437-445 (1950).

4. Weertman, J., J. Appl. Phys., 28, 362-364 (1957).

5. Kingery, W. D. and Coble; R. L., "A Review of the Effect of Microstructure on Mechanical Behavior of Polycrystalline Ceramics," in "Mechanical Behavior of Crystalline Solids, "U.S. Department of Commerce, National Bureau of Standards Monograph 59, March 25, 1963, pp. 103-111.

6. Wolfe, R. A. and Kaufman, S. F., "Mechanical Properties of Oxide Fuels (LSBR/LWB Development Program)," WAPD-TM-587 AEC Research and Development Report, October 1967.

7. Armstrong, W. M., Causey, A.R., and Sturrock, W. R., J. Nucl. Mater. , 19, 42-49 (1966).

8. Scott, R., Hall, A.R., and Willtams, J., J. Nucl. Matcr., 1, 39-48 (1959).

9. Armstrong, W. M., Irvine, W. R., Martinson, R. H. , J. Nucl. Mater., 2, 133-141 (1962).

10. Poteat, L. E. and Yust, C. S., "Gralu Büundary Rcactione During Deformation," ORNL-P=327.1, 1 ก65.

11. Alcock, C. B., Hawkins, R. J., Hills, A.W.D., and McNamara, P., "A Study of Cation Diffusion in Stoichiometric $\mathrm{UO}_{2}$ Using $\alpha$-ray Spectrometry," Proceedings on the Symposium of Thermodynamics, International Atomic Energy Agency, Vienna, 1966, pp. 57-72.

12. Belle, J. Auskern, A. B., Bostrum, W. A., and Susko, F. S., 4th Intern. Conf. Reactivity of Solids, Elsevier, Amsterdam, 1960, p. 452.

13. Lidiard, A. B., J. 'Nucl. Mater., 19, 106-108 (1966).

14. Hilliard, J. E., "Grain Size Estimation," General Electric Research Lab., Dept. No. 62-RL-3133M (1962).

15. Brophy, .J. H., Rose, R. M., and Wulff, J., "The Structure and Properties of Materials," John Wiley and Sons, New York, 1964, Vol. II, pp. 82-84.

16. J. R. Mat Ewan and V. B. Laweon, J. Ampr C.ramic Soc. . 45, 37-41 (1962). 


\section{DISTRIBUTION LIST}

Director, Contracts Division

U. S. Atomic Energy Commission

San Francisco Operations Office

2111 Banicroft Way

Berkeley, California 94704

Chief, California Patent Croup

U. S. Atomic Energy Commission

San Francisco Operations Office

P. O. Box 808 .

Livernore, California 94551

Division of Reactor Development and Technology

U. S. Atomic Energy Commission

Washington, D. C. 20545

Attn: Asst. Director for Reactor Engineering

Division of Reactor Development and Technology

U. S. Atomic Energy Commission

Washington, D. C. 20545

Attn: M. J. Whitman

Asst. Director for Program Analysis

Division of Reactor Development and Technology

U. S. Atomic Energy Commission

Washington, D. C. 20545

Attn: A. Giambusso

Asst. Director for Project Mgmt

(Attn: R. Sweek, G. Wensch, J. Morabito)

Division of Reactor Development and Technology

U. S. Atomic Energy Commission

Washington, D. C. 20545

Attn: J. A. Lieberman

Asst. Director for Nuclear Safety

Division of Reactor Development and Technolngy

U. S. Atomic Energy Commission

Washington, D. C. 20545

Attn: J. A. Lieberman

Asst. Director for Nuclear Safety

Division of Reactor Development and Technology

U.S. Atomic Linergy Commission

Washington, D. C. 20545

Attn: J. W. Crawford

$\Lambda$ sest. Director fur Plant Enginearing
2 Division of Reactor Development and Technology

U.S. Atomic Energy Commission

Washington, D. C. 20545

Attn: K. H. Steel

Division of Naval Reactors

1. Division of Reactor Development and Technology

U.S. Atomic Energy Commission

Washington, D. C. 20545

Attn: E. E. Sinclair

Asst. Director for Reactor Tech.

(Attn: J. M. Simmons; I. Zartman)

2

RDT Site Office

U.S. Atomic Energy Commission

c/o General Electric Company

1310 DeGuigne Drive

Sunnyvale, California

Attn: J. V. Levy

LMFBR Program Office

Argonne National Laboratory

39800 South Cass Avenue

Argonne, Illinois 60439

Attn: A. Amorosi, Director

LMFBR Program Office

Argonne National Laboratory

9800 South Cass Avenue

1 Argonne, Illinois 60439

Attn: L. R. Kelman

Atomics International

P.O. Box 309

Canoga Park; California 91304

1 Attn: S. Golan

Director

Liquid Metals Information Center

P. O. Box 309

Canoga Park, California 91305

1

The Babcock \& Wilcox Company

Atomic Energy Division

Lynchburg, Virginia 24501

Attn: M. W. Ciroft 
Mr. L. W. Fromm, Manager

1000 MWe LMFBR Follow-On Study Project Building 208

Argonne National Laboratory 9800 South Cass Avenue

Argonne, Illinois 60439

Mr. C. A. Anderson, Project Mgr 1000 MWe LMFBR Follow-On Study

Westinghouse Electric Corporation

Advanced Reactors Division

Waltz Mill Site

P. O. Box 158

Madison, Pennsylvania 15663

FFTF Project

P. O. Box 220

Richland, Washington 99352

Attn: Configuration \& Data Management

W. P. Staker, Project Manager

1000 MWe LMF BR Follow-On Study

Combustion Engineering, Inc.

P. O. Box 500

Windsor, Connecticut 06095

RDT Senior Site Representative

Canuga Fark Area Office

P. O. Box 2325

San Diego, Cadifornia 92112

RDT Senior Site Representative

Cannga Park Area ()ffice

P. O. Box 591

Canoga Park, California 91305

RDT Senior Site Representative

U.S. Atomic Energy Commission

Argonne National Iahoratory

9800 South Cass Avenue

Argonne, Illinois 60439

IUT Site Officc

U.S. Atomic Energy Commission

Atomic Power Development Associates, Inc.

1911 First Street

Detroit, Michigan 48226

RDT Senior Site Representative

Oak Ridge National Laboratory

P. O. Box X

Oak Ridge, Tennessec 37830

The Babcock \& Wilcox Company

Atomic Energy Division

Lynchburg, Virginia 24501

Attn: S. H. Esleeck
2 RDT Senior Site Representative

U.S. Atomic Energy Commission

P. O. Box 550

Richland, Washington 99352

RDT Site Representative

1

U.S. Atomic Energy Commission

Post Office Box 2108

Idaho Falls, Idaho 83401

RDT Site Representative

U.S. Atomic Energy Commission

United Nuclear Corporation

Grasslands Road

Elmsford, New York 10523

8 Alln: M. Napack

R.DT Site Representative

U.S. Atomic Energy Commission

United Nudear Corporation

2 Grasslands Road

Elmsford, New York 10523

Attn: A Strasser

Argonne National Laboratory

19800 South Cass Avenue

Argonne, Illinois 60439

$\Lambda$ ttn: J. H. Kittel

Argonne Nátional Laboratory

19800 South Cass Avenue

Argonnc, Illinuis 60439

Attn: R. C. Vogel

Pacific Northwest Laboratory

P. O. Box 999

Richland, Washington 99352

Attn: E. A. Eschbach

Pacific Northwest Laboratory

P.0. Box 999

1 Truchland, Washington 99352

Attn: E. A. Evans

University of California

Lawrence Radiation Laboratory

P. 0. Box 808

Livermore, California 94551

Attn: A. Rothman

Los Alamos Scientific Laboratory

1

P. 0. Box 1663

Los Alamos, New Mexico 87544

Attn: R. D. Baker 
I.os Alamos Scientific Laboratory P. O. Box 1663

Los Alamos, New Mexico 87544

Attn: D. B. Hall

Los Alamos Scientific Laboratory P. O. Box 1663

Los Alamos, New Mexico 87544,

Attn: J. C. Clifford

Scientific Laboratory

P. O. Box 1.663

Los Alamos, New Mexico 87544

Attn: Reports Librarian

Westinghouse Electric Corporation Bettis Atomic Power Laboratory P. O. Box 79

West Mifflin, Pennsylvania

Attn: E. J. Kreh

Oak Ridge National Laboratory

P. O. Box X

Oak Ridge, Tennessee 37830

Attn: J. E. Cunningham

Brookhaven National Laboratory

Upton, Ncw York 11973

Attn: O. E. Dwyer

Battelle Memorial Institute

Columbus Laboratories

505 King Avenue

Columbus, Ohio 4.3201

$\Lambda$ ttn: D. Keller

Atomics International

P. O. Box 309

Canoga Park, California 91304

Attn: H. Pearlman

Atomics International

P. 0. Box 309

Canoga Park, Culifornia 91304

Attn: FBR Project Manager

(R. J. Beeley)

Dow Chemical Company

Rock Flats Division

P. O. Box 888

Golden, Colorado 80401

Attn: R. D. Forest
1 Scientific Representative

U.S. Atomic Energy Commission

American Embassy

APO San Francisco 96503

1 U.S. AEC Scientific Representative

1

United States Embassy

Paris, France

APO New York 09777

1 Senior U.S. AEC Representative

1

U.S. Mission to the European Communities

United States Embassy

Brussels, Belgium

1 Division of Technical Information Ext.

U.S. Atomic Energy Commission

P. O. Box 62

Oak Ridge, Tennessee 37831

Dr. John C. Woodhouse

1

11 Guest Lane

Wilmington, Delaware 19809

Power Reactor Development Corp.

1

1911 First Street

1 Detroit, Michigan 48226

Attn: W. J. McCarthy

1 Argonne National Laboratory

1

P. O. Box 1096

Idaho Falls, Idaho 83401

Attn: F. W. Thalgott

1

Detroit Edison Company

1911 First Street

Detroit, Michigan 49226

Attn: A. S. Griswold

1

Atomic Power Development Associates

1911 First Street.

Detruil, Michigan 48220

Attn: A. A. Shoudy

1 Combustion Engineering, Inc.

1

Nuclear Division

Prospect Hill Road

Windsor, Connecticut 06005

Attn: W. P. Chernock 
The Babcock \& Wilcox Company

Atomic Energy Division

l.ynchburg, Virginia 24501

Attn: H. S. Barringer

General Atomic

P. O. Box 608

San Diego, California 92112

Attn: D. B. Coburn

The Babcock \& Wilcox Company

Alliance Research Center

Alliance, Ohịo 44601

Attı: D. Kuch

Westinghouse Electric Corporation

Advance Reactors Division

P. O. Box 217

Cheswick, Pennsylvania 15024

Attn: W. E. Ray

Nuclear Materials \& Equipment Corp.

Plutonium Laboratory

Leechburg, Pennsylvania 15656

Attn: William J. Ross
1 U. S. AEC Scientific Representative 1 United States Embassy

London, England

l

S. F. Stachura

Villa Plein Ciel

Quartier Roussier

Aix-en-Provence

113 - France

S. Vistrer

2

Nuclear Division

1 Combustion Engintering, Inc.

P. O. Box 500

Windsor, Connecticut 06095

W. B. Cottrell, Director

1 Nuclear Safety Program

Oak Ridge National Laboratory

P.O. Box Y

Oak Ridge, Tennessee 37830 